\title{
Exenatide regulates pancreatic islet integrity and insulin sensitivity in the nonhuman primate baboon Papio hamadryas
}

Teresa Vanessa Fiorentino,, ${ }^{1,2}$ Francesca Casiraghi, ${ }^{2,3}$ Alberto M. Davalli, ${ }^{2,4}$ Giovanna Finzi, Stefano La Rosa, ${ }^{6}$ Paul B. Higgins, ${ }^{7}$ Gregory A. Abrahamian, ${ }^{8}$ Alessandro Marando, ${ }^{5}$ Fausto Sessa, ${ }^{5}$ Carla Perego, ${ }^{9}$ Rodolfo Guardado-Mendoza, ${ }^{2}$ Subhash Kamath, ${ }^{2}$ Andrea Ricotti, ${ }^{2}$ Paolo Fiorina, ${ }^{10}$ Giuseppe Daniele, ${ }^{2}$ Ana M. Paez, ${ }^{2}$ Francesco Andreozzi, ${ }^{1,2}$ Raul A. Bastarrachea, ${ }^{7}$ Anthony G. Comuzzie, ${ }^{7}$ Amalia Gastaldelli, ${ }^{2,11}$ Alberto O. Chavez, ${ }^{2}$ Eliana S. Di Cairano, ${ }^{9}$ Patrice Frost, ${ }^{7}$ Livio Luzi,, ${ }^{3,12}$ Edward J. Dick,, Glenn A. Halff, ${ }^{7}$ Ralph A. DeFronzo, ${ }^{2}$ and Franco Folli ${ }^{2,7,13}$

'Department of Medical and Surgical Sciences, University Magna Graecia of Catanzaro, Catanzaro, Italy. ${ }^{2}$ Division of Diabetes, Department of Medicine, University of Texas Health Science Center at San Antonio, San Antonio, Texas, USA. ${ }^{3}$ Department of Biomedical Sciences for Health, University of Milan, Milan, Italy. ${ }^{4}$ Department of Medicine, Endocrinology Unit, Ospedale San Raffaele, Milan, Italy. ${ }^{5}$ Unit of Pathology, Ospedale di Circolo and Department of Medicine and Surgery, University of Insubria, Varese, Italy. ${ }^{6}$ Service of Clinical Pathology, Institute of Pathology, Lausanne University Hospital and University of Lausanne, Lausanne, Switzerland. 'Touthwest National Primate Research Center, Texas Biomedical Research Institute, San Antonio, Texas, USA. ${ }^{8}$ Department of Surgery, Transplant Center, University of Texas Health Science Center at San Antonio, San Antonio, Texas, USA. 'Department of Pharmacology and Biomolecular Science, University of Milan, Milan, Italy. ${ }^{10}$ Boston Children's Hospital, Harvard Medical School, Boston, Massachusetts, Division of Health Science, Harvard University, Boston, Massachusetts, USA. "Institute of Clinical Physiology, National Research Council, Pisa, Italy. ${ }^{12}$ Metabolism Research Centre, IRCCS Policlinico San Donato, Milan, Italy. ${ }^{13}$ Department of Health Science, University of Milan, Milan, Italy.

Authorship note: TVF, FC, and AMD are co-first authors.

Conflict of interest: The authors have declared that no conflict of interest exists.

Copyright: (c) 2019, American Society for Clinical Investigation.

Submitted: January 29, 2019 Accepted: September 5, 2019 Published: September १९, 2019.

Reference information: JCl Insight. 2019;4(20):e93091. https://doi.org/10.1172/jci. insight.93091.
The glucagon-like peptide-1 receptor agonist exenatide improves glycemic control by several and not completely understood mechanisms. Herein, we examined the effects of chronic intravenous exenatide infusion on insulin sensitivity, $\beta$ cell and $\alpha$ cell function and relative volumes, and islet cell apoptosis and replication in nondiabetic nonhuman primates (baboons). At baseline, baboons received a 2-step hyperglycemic clamp followed by an L-arginine bolus (HC/A). After HC/A, baboons underwent a partial pancreatectomy (tail removal) and received a continuous exenatide $(n=12)$ or saline ( $n=12$ ) infusion for 13 weeks. At the end of treatment, HC/A was repeated, and the remnant pancreas (head-body) was harvested. Insulin sensitivity increased dramatically after exenatide treatment and was accompanied by a decrease in insulin and C-peptide secretion, while the insulin secretion/insulin resistance (disposition) index increased by about 2 -fold. $\beta, \alpha$, and $\delta$ cell relative volumes in exenatide-treated baboons were significantly increased compared with saline-treated controls, primarily as the result of increased islet cell replication. Features of cellular stress and secretory dysfunction were present in islets of saline-treated baboons and absent in islets of exenatide-treated baboons. In conclusion, chronic administration of exenatide exerts proliferative and cytoprotective effects on $\beta, \alpha$, and $\delta$ cells and produces a robust increase in insulin sensitivity in nonhuman primates.

\section{Introduction}

Type 1 and type 2 diabetes (T1D, T2D) are characterized by progressive $\beta$ cell dysfunction coupled with declining $\beta$ cell mass $(1,2)$. At the time of T2D diagnosis, $\beta$ cell function is reduced by about $80 \%(3)$ and $\beta$ cell mass is reduced to $30 \%-50 \%(4,5)$, while in T1D the $\beta$ cell deficit is severer and averages $70 \%-100 \%(6)$. 
A dimorphic histology of long-duration T1D has been reported, with $70 \%$ of subjects showing only insulin-deficient islets and the remaining $30 \%$ showing numerous insulin-positive cells $(7,8)$. Importantly, residual $\beta$ cell function has been demonstrated 30-40 years after the onset of T1D with ultrasensitive C-peptide assays (9). Nevertheless, the loss of $\beta$ cells remains fundamental to the etiology of both forms of diabetes.

Preventing the loss and enhancing proliferation of $\beta$ cells is essential for maintaining long-term metabolic control in T1D and T2D. However, the 2 most commonly prescribed antidiabetic drugs (metformin and sulfonylureas) are not effective in this regard (10-14), and sulfonylureas may even promote $\beta$ cell loss (15). Synthetic long-acting glucagon-like peptide-1 (GLP-1) receptor agonists (GLP-1 RAs) exhibit glucoregulatory activities similar to native GLP-1, including glucose-dependent enhancement of insulin secretion and inhibition of glucagon release, delayed gastric emptying, and reduced food intake (16-19). Importantly, GLP-1 RAs also show proliferative effects, including enhanced $\beta$ cell replication and reduced apoptosis (20). Nevertheless, these in vivo cellular findings have been described only in rodents, although in vitro evidence for these effects has been reported in human tissues (21-26). It is unknown whether GLP-1 RAs can stimulate $\beta$ cell growth in vivo in humans, and the tissue sampling required to directly test these effects in a controlled setting is excessively invasive.

The baboon is recognized as an important preclinical model of human obesity, insulin resistance, and T2D that provides high translational value (27-31). Compared with other species, the relative volume, distribution, and responses of islet cells are more consistent between human and nonhuman primates (32). In the present study, we generated a partially pancreatectomized model of diminished $\beta$ cell mass and islet cellular stress in baboons and tested the in vivo effects of chronic administration of the GLP-1 RA exenatide on: (a) islet cell replication, apoptosis, transdifferentiation (neogenesis), and ultrastructural integrity; (b) $\alpha$ and $\beta$ cell secretory function; and (c) insulin sensitivity. Our results provide the first direct in vivo evidence, we believe, for enhanced $\beta$ cell replication, decreased apoptosis, and reduced cellular stress following chronic GLP-1 RA administration in a nonhuman primate.

\section{Results}

Body composition and plasma chemistries. The study population comprised 28 female nondiabetic baboons (Papio hamadryas sp.). Twenty-four animals underwent abdominal surgery with resection of the pancreatic tail (partial pancreatectomy $[\mathrm{PPx}]$ ) and then were randomized to receive a chronic (13-week) intravenous infusion of saline $(n=12)$ or exenatide $(n=12)$. Four animals underwent sham abdominal surgery without PPx followed by a chronic saline intravenous infusion (sham-operated, saline-treated [SHAM]) for 13 weeks.

At the end of the study, serum exenatide levels were higher $(758 \pm 162 \mathrm{pg} / \mathrm{mL})$ in the exenatide group compared with the saline group $(0.0 \mathrm{pg} / \mathrm{mL})$. Body weight was significantly lower in the saline-treated group $(16.7 \pm 0.7 \mathrm{~kg}$ vs. $18.5 \pm 0.7 \mathrm{~kg}, P=0.01)$ at study end, whereas it did not change significantly in the exenatide group $(17.2 \pm 0.6 \mathrm{~kg}$ vs. $18.2 \pm 0.8 \mathrm{~kg}, P=0.08)$ (Supplemental Figure 1A; supplemental material available online with this article; https://doi.org/10.1172/jci.insight.93091DS1). Body composition analysis showed that lean mass was maintained in the exenatide group $(15.2 \pm 0.5 \mathrm{~kg}$ vs. $15.6 \pm 0.4 \mathrm{~kg}, P=0.24)$ but decreased in the saline-treated control baboons $(16.1 \pm 0.5 \mathrm{~kg}$ vs. $15.0 \pm 0.6 \mathrm{~kg}, P=0.03$, Supplemental Figure 1B). A significant decrease in fat mass was observed after treatment with exenatide $(1.54 \pm 0.45$ vs. $0.93 \pm 0.20 \mathrm{~kg}, P \leq 0.05)$ and saline (1.27 \pm 0.24 vs. $0.86 \pm 0.21 \mathrm{~kg}, P \leq 0.05$, Supplemental Figure $1 \mathrm{C})$. The SHAM group did not undergo any significant changes in body composition or body weight over the study period. Food consumption was similar in the 3 groups, indicating that exenatide did not decrease energy intake (Supplemental Figure 1D). No anorexia, vomiting, diarrhea, or behavior changes were observed in animals treated with exenatide or saline. Clinical chemistries assessed before and after treatments did not show any significant change in the 3 study groups (Table 1). Specifically, there was no increase in plasma amylase after exenatide treatment. A decrease in $\mathrm{Hb}$ was observed in both saline- and exenatide-treated groups with no significant difference in $\mathrm{Hb}$ changes between the 2 study arms, suggesting that surgery and long-term catheterization may have contributed to the decrease in $\mathrm{Hb}$.

Exenatide improved $\beta$ cell function and insulin sensitivity and induced $\beta$ cell rest. Plasma insulin and C-peptide concentrations during the 2-step hyperglycemic clamp are shown in Figure 1, A-F. The insulin secretory rate (ISR) (150-180 minutes) decreased significantly after exenatide treatment $(149 \pm 17 \mathrm{pmol} / \mathrm{kg} / \mathrm{min}$ vs. $111 \pm 16 \mathrm{pmol} /$ $\mathrm{kg} / \mathrm{min}, P<0.01)$ and did not change in the saline-treated $(116 \pm 11 \mathrm{pmol} / \mathrm{kg} / \mathrm{min}$ vs. $104 \pm 10 \mathrm{pmol} / \mathrm{kg} / \mathrm{min}$, $P=0.20)$ and SHAM $(165 \pm 9 \mathrm{pmol} / \mathrm{kg} / \mathrm{min}$ vs. $184 \pm 27 \mathrm{pmol} / \mathrm{kg} / \mathrm{min}, P=0.47)$ control groups. Plasma insulin and C-peptide concentrations were significantly lower $(P<0.05)$ after exenatide treatment at multiple 
Table 1. Effects of treatments with exenatide, saline, and SHAM normal-glucose tolerant baboons on several metabolic and clinical chemistry parameters

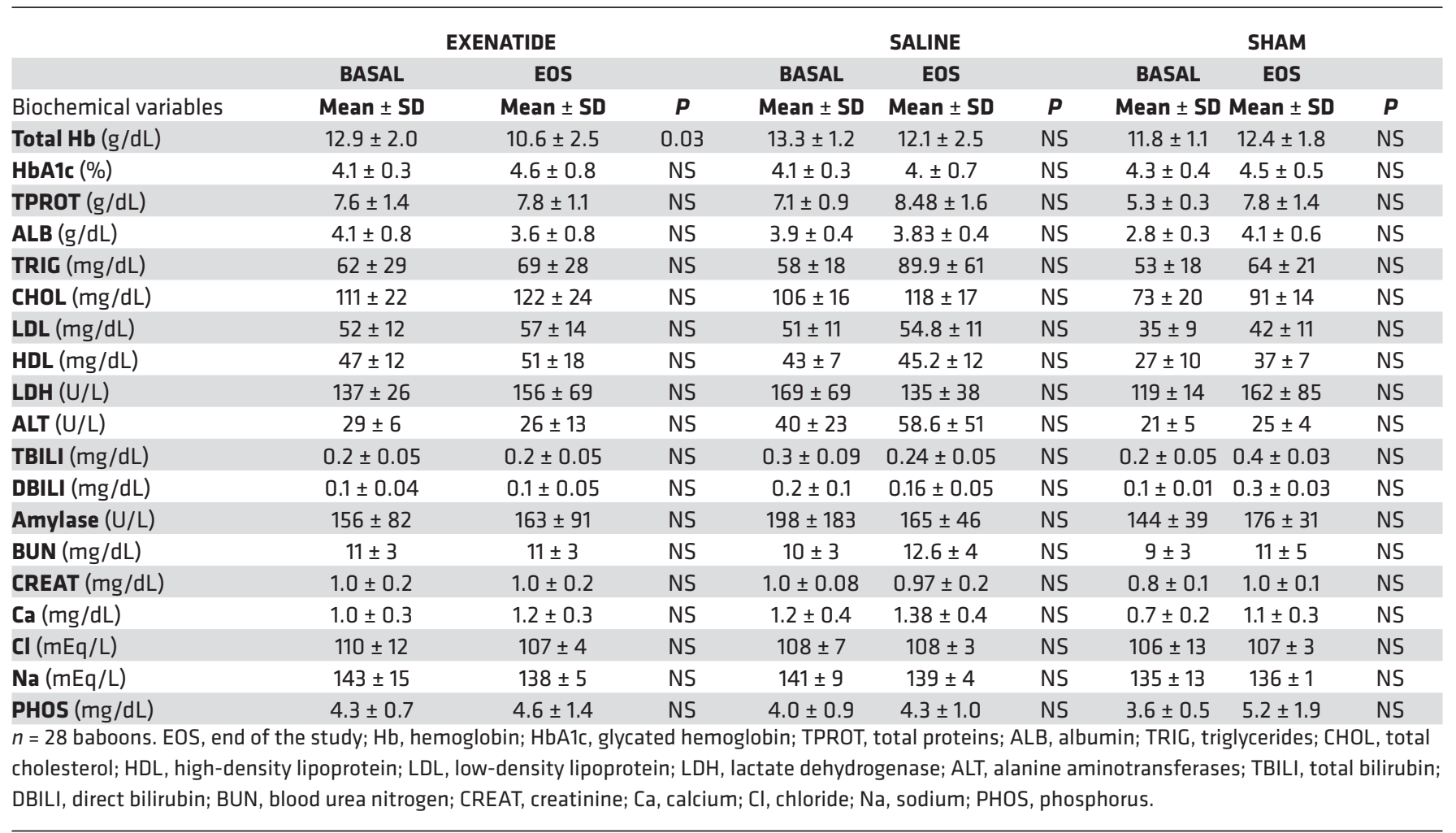

time points during the hyperglycemic clamp (Figure 1, A and B), including during the arginine stimulation test (180-210 minutes). There were no significant changes in either the plasma insulin or C-peptide responses in the saline-treated (Figure 1, C and D) or SHAM (Figure 1, E and F) groups. Similar results were obtained whether one used the periods of 90-180, 0-90, or 60-90 minutes. No significant differences in the plasma glucose levels during the hyperglycemic clamp were observed between the 3 study groups (Supplemental Figure 2A). Plasma glucagon concentrations were not changed after treatment in any of the groups (Supplemental Figure 2B). The AUC for plasma insulin and C-peptide concentrations (0-210 minutes) was significantly reduced by exenatide treatment while no significant changes were observed in saline-treated and SHAM groups (Figure 2, A and B).

Exenatide treatment resulted in a marked improvement in whole-body insulin sensitivity as demonstrated by the insulin-stimulated glucose disposal $(\mathrm{M})$ and the increased ratio of $\mathrm{M}$ value and insulin concentrations during the clamp procedure (M/I; refs. 3, 27, 29) after treatment compared with baseline (Figure 2C and Supplemental Figure 3A); this could not be explained by changes in body weight or body composition. After exenatide treatment $\beta$ cell function, estimated by the insulin secretion/insulin resistance (disposition) index (calculated by multiplying the ISR by insulin sensitivity) increased almost 2-fold (Figure 2D). No differences in insulin sensitivity or insulin secretion were found after treatment in the saline-treated and SHAM control groups (Figure 2, C and D). The relationship between insulin sensitivity and insulin secretion at baseline and after treatment for the 3 study groups is shown in Supplemental Figure 3B. No significant differences in hepatic insulin clearance were found between baseline and study end in each study group (Supplemental Figure 3C).

Western blot analysis revealed that in skeletal muscle the only significant change in insulin signaling proteins was an increase in Akt $\mathrm{Ser}^{473}$ phosphorylation in exenatide-treated animals $(P=0.03)$ (Supplemental Figure 4). Expression and phosphorylation of the other key proteins involved in insulin signaling, including insulin receptor- $\beta$ (IR- $\beta$ ), insulin receptor substrate-1 (IRS-1), extracellular signal-regulated kinase (ERK), Jun N-terminal kinase (JNK), phosphatase and tensin homolog (PTEN), and PH domain and leucine-rich repeat-containing protein phosphatase 1 (PHLPP1) did not differ between exenatide- and saline-treated groups. In livers of exenatide-treated animals, the only significant change was a decrease in ERK phosphorylation $(P=0.03)$ (Supplemental Figure 5). 
A

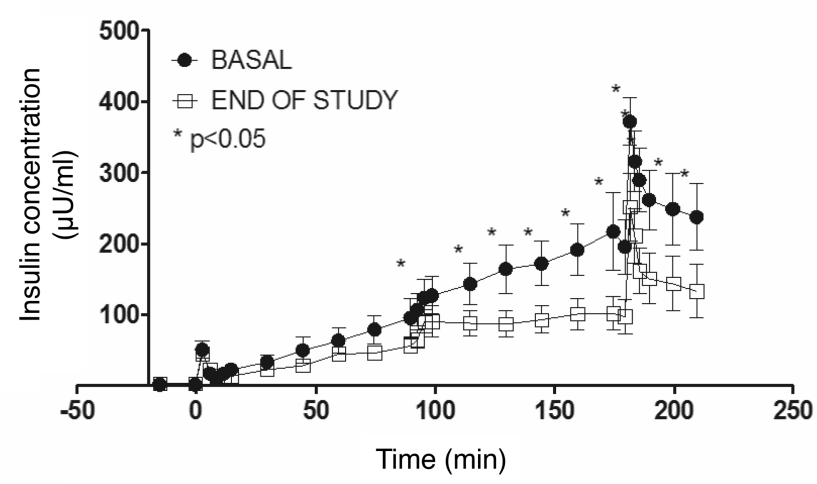

C

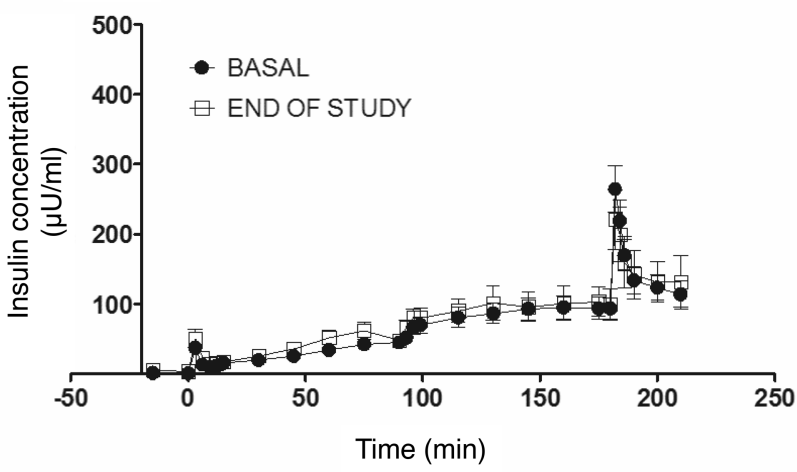

E

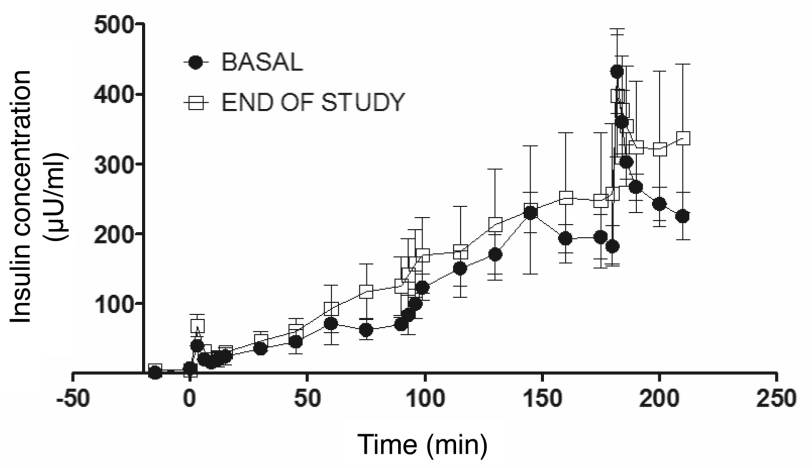

B

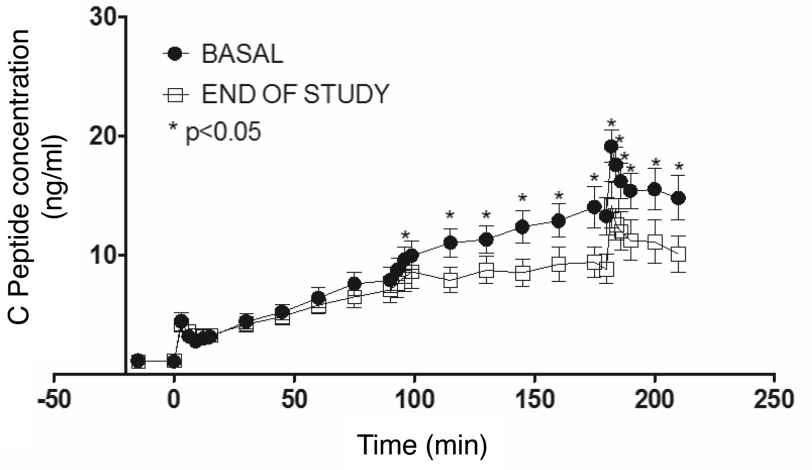

䍜

D

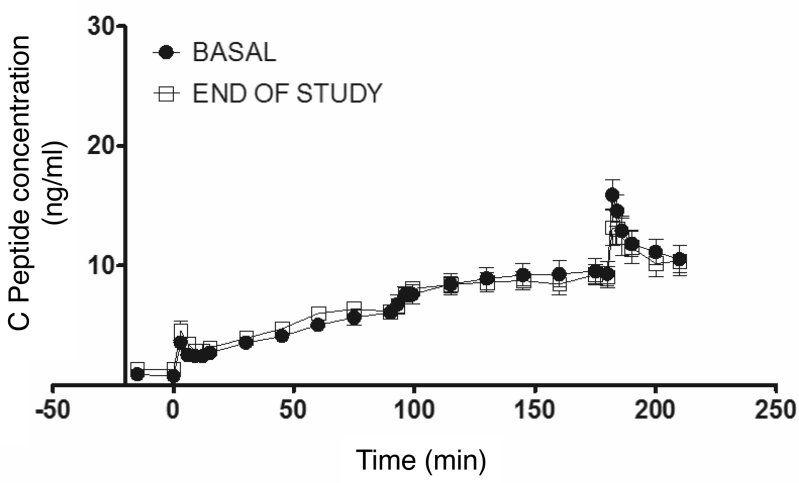

$\frac{\infty}{\sum}$

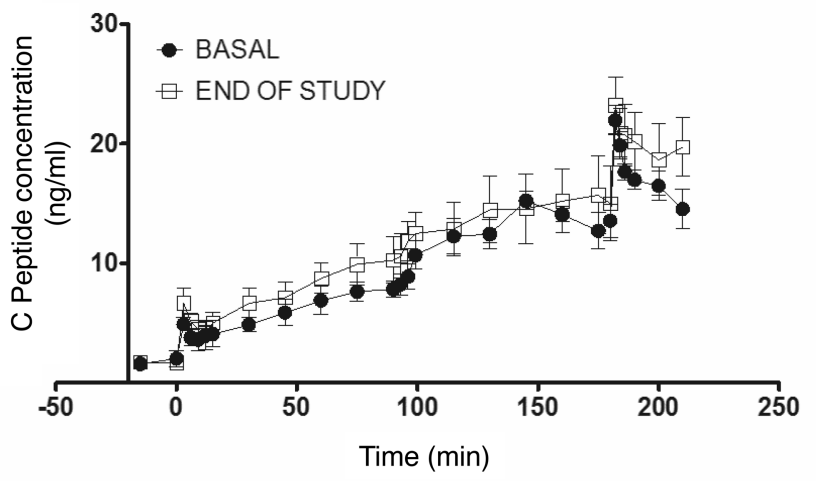

$\frac{\infty}{I}$

Figure 1. Effect of exenatide on insulin and C-peptide secretion. Dynamics of insulin (A, C, E) and C-peptide (B, D, F) secretion during the 2-step hyperglycemic clamps performed before $(\bullet)$ and after $(\square)$ treatments with exenatide (left), saline (middle), and saline in SHAM-operated (right) baboons. Number of baboons: 12 in exenatide group, 12 in saline group, and 4 in SHAM group. Comparisons between baseline and after-treatment data were performed by Wilcoxon's test. ${ }^{*} P<0.05$.

Exenatide promoted islet cell replication and differentiation and reduced apoptosis. Of particular note, in baboons that served as anatomic controls, islet $\beta$ cell and $\alpha$ cell volumes in the head-body were significantly reduced (by $25 \%-33 \%$ ), compared with the tail, while $\delta$ cell volumes were not different between regions (Figure 3A). In baboons that received saline for 13 weeks, at study end islet volume in the head-body region was significantly reduced compared with the tail region (Figure 3B). In exenatide-treated baboons, at study end islet volume in the head-body region was unchanged compared with the tail region (Figure 3B), and, importantly, it was higher than that in the head-body region of saline-treated animals $(P=0.02$, Figure $3 \mathrm{~B})$. Notably, because islet volume in anatomic controls and saline-treated baboons is normally lower in the head-body versus tail, an "unchanged" islet volume in 
A

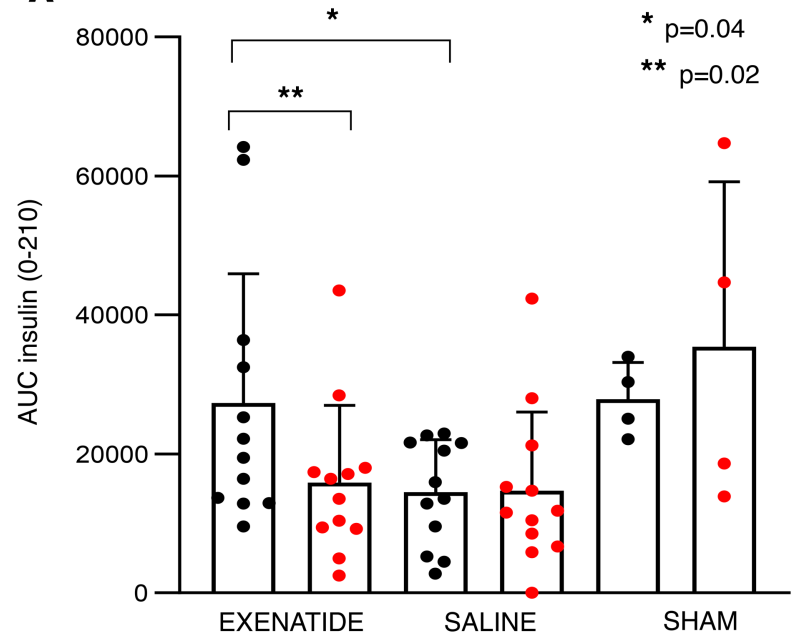

C

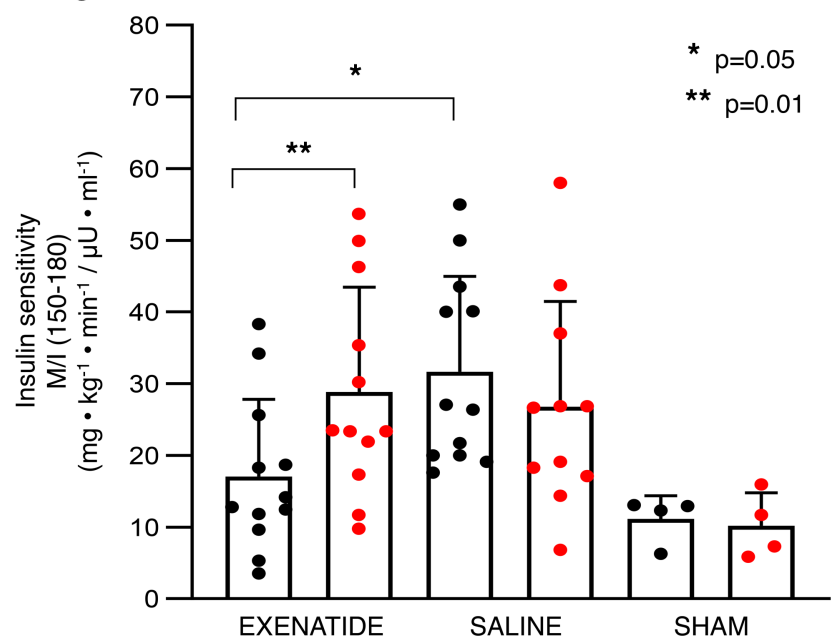

B

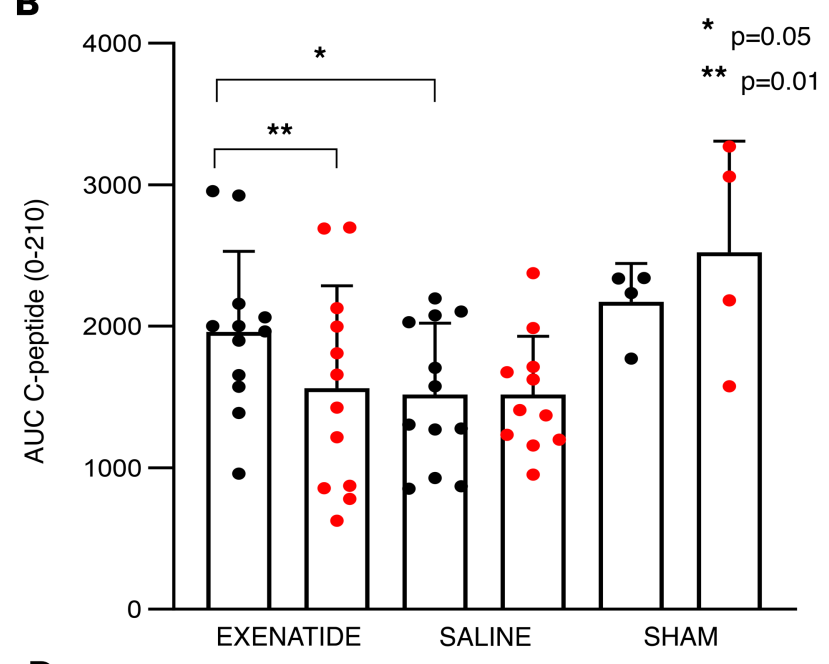

D

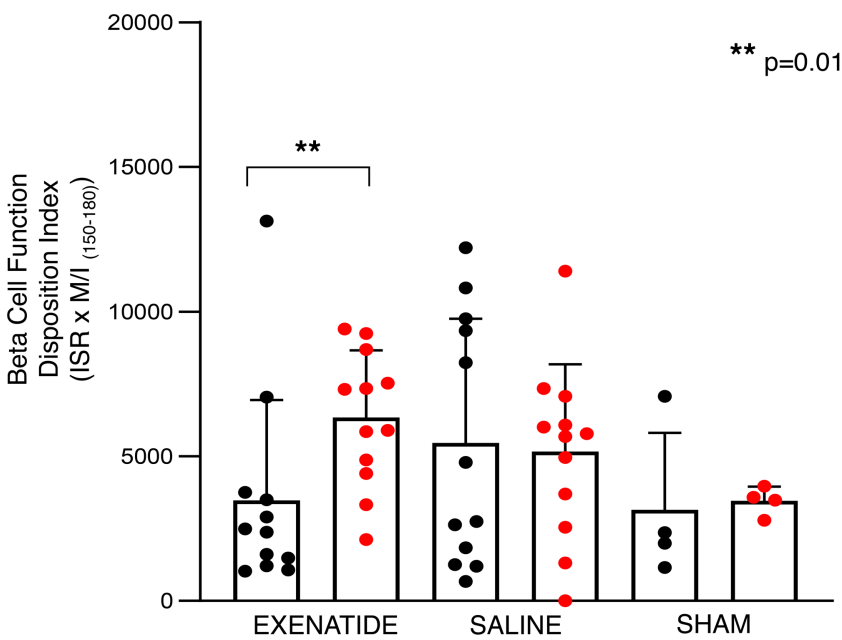

Figure 2. Effect of exenatide on insulin secretion and sensitivity. (A) AUC insulin, (B) AUC C-peptide, (C) insulin sensitivity index (M/I), and (D) disposition index during the 2-step hyperglycemic clamp with arginine stimulation performed before (shown in black) and after (shown in red) treatment with exenatide or saline and in SHAM-operated baboons. Number of baboons: 12 in exenatide group, 12 in saline group, and 4 in SHAM group. Comparisons between baseline and after-treatment data were performed by Wilcoxon's test. Comparison of clinical data between the study groups was performed by using a general linear model for multiple comparisons with adjustment for age and body weight. ${ }^{*} P \leq 0.05 ;{ }^{* *} P \leq 0.01$

the exenatide group indicates a growth-promoting effect of exenatide on islet volume. In saline-treated baboons, at study end $\beta$ cell volume in the head-body region also was significantly reduced compared with the tail region $(3.1 \pm 0.8 \%$ vs. $5.5 \pm 1.6 \%, P=0.003$, Figure $3 C)$. In marked contrast, at study end $\beta$ cell volume in the head-body of pancreata from exenatide-treated animals was not significantly different from that in the tail before treatment ( $5.6 \pm 2.6 \%$ vs. $4.7 \pm 1.6 \%$, Figure $3 \mathrm{C})$, and it was significantly increased compared with the $\beta$ cell volume in the head-body region of the anatomic control group $(4.7 \pm 1.6 \%$ vs. $3.2 \pm 1.2 \%, P=0.01)$ and of saline-treated baboons $(4.7 \pm 1.6 \%$ vs. $3.1 \pm 0.8, P$ $=0.01$ ), indicating a positive effect of exenatide on $\beta$ cell proliferation. Similar changes were observed for $\alpha$ cell volumes (saline group: $2.6 \pm 1.7$ vs. $0.7 \pm 0.6 \%, P=0.003$; and exenatide group: $2.1 \pm 1.4 \%$ vs. $1.6 \pm 0.9 \%, P=$ NS; $P=0.02$ for exenatide vs. saline at the study end, Figure $3 \mathrm{D}$ ) and for $\delta$ cell volumes (saline group: $0.7 \pm 0.4 \%$ vs. $0.3 \pm 0.3 \%, P=0.002$; and exenatide group: $0.7 \pm 0.6 \%$ vs. $0.8 \pm 0.2 \%, P=\mathrm{NS} ; P=0.04$ for exenatide versus saline group at the study end; Figure $3 \mathrm{E})$. Further, when adjusted for changes in $\beta$ cell volume, insulin secretion (insulin secretion AUC/ $\beta$ cell volume) was decreased by $32 \%$ of the basal level in the exenatide-treated group, indicating an unloading of the $\beta$ cell, while insulin secretion (AUC) $/ \beta$ cell volume increased by $81 \%$ of the basal value in the saline-treated group (Table 2), indicating hyperstimulation. 
A

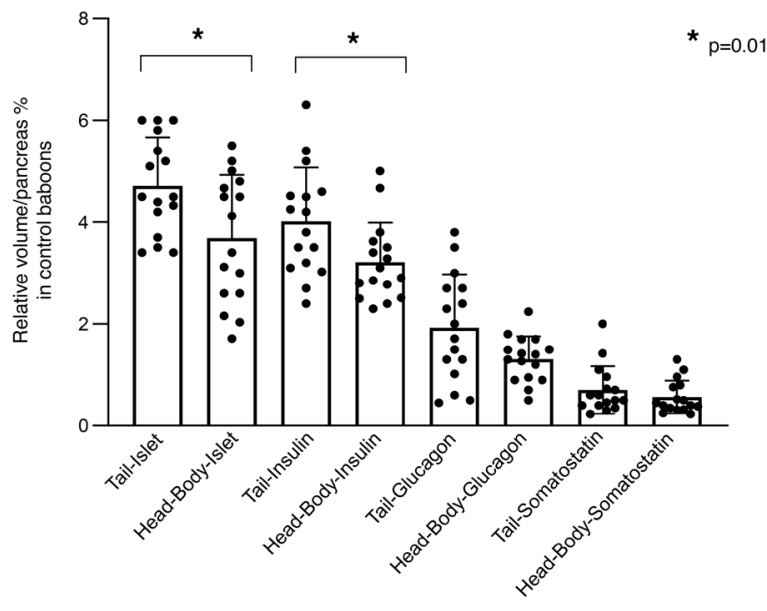

C

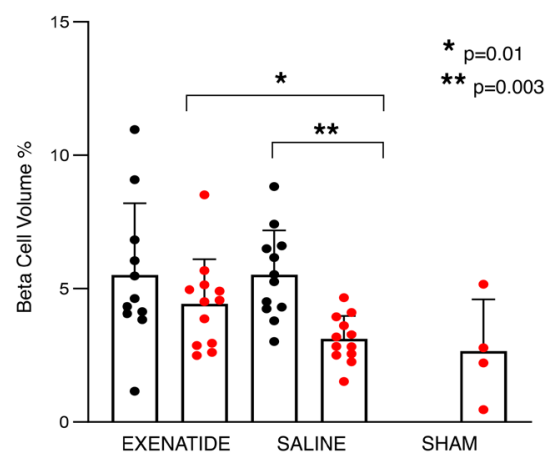

D

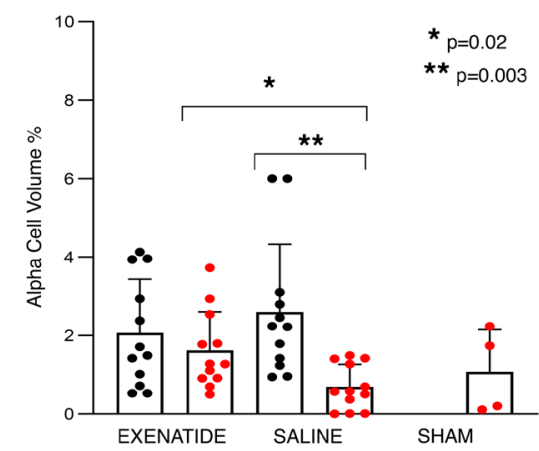

B

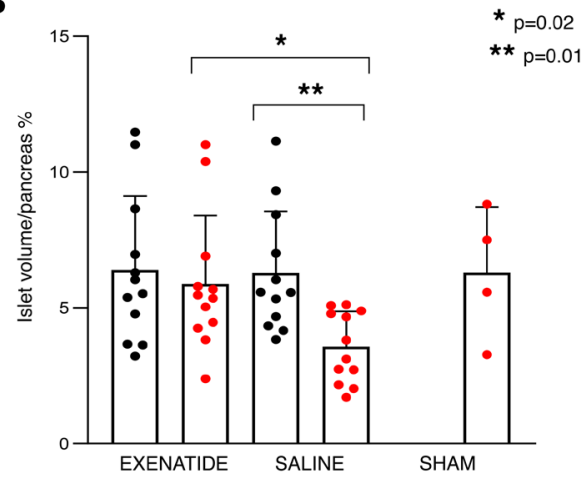

E

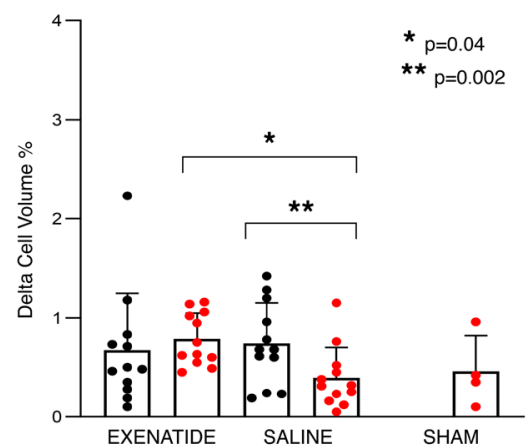

Figure 3. Effect of exenatide on pancreatic islet volumes. (A) The anatomic composition/relative volume of pancreatic islet from different regions of the pancreas obtained in animal/baboon controls. (B) Whole-islet volumes before (black) and after (red) the different treatments are shown. (C-E) The $\beta$ cell, $\alpha$ cell, and $\delta$ cell volumes before (black) and after (red) treatment in the 3 groups. Islet volume and relative islet $\beta, \alpha$, and $\delta$ cell volume were assessed by using computer assisted stereology toolbox (CAST) and expressed as percentage of total pancreas. Number of sections for each baboon: 10 ( 5 sections at baseline and 5 sections at the end of the study) evaluated twice. Comparisons between baseline and after-treatment data for each study group were performed by Wilcoxon's test. A general linear model for multiple comparisons adjusted for age and body weight was used to test differences in relative islet/cell volumes between exenatide- versus saline-treated animals.

To examine potential mechanisms responsible for the growth-promoting effect of exenatide, we stained pancreatic sections with replication and apoptosis markers Ki67/MIB-1 and M30, respectively (Supplemental Figure 6, A and B, and Figure 4, A-C). We observed a marked increase in the percentage of islet cells undergoing replication in the exenatide group, while there was no change in Ki67 ${ }^{+}$cells in the saline controls (Figure 4A). Using immunofluorescence, the replication marker Ki67 colocalized with insulin-positive cells, confirming that $\beta$ cells were among the islet cells undergoing replication with exenatide treatment (Supplemental Figure 7). Further, we observed that the replication marker Ki67 colocalized with glucagon-positive cells in exenatide-treated baboons (Supplemental Figure 8), indicating that treatment with exenatide also stimulated $\alpha$ cells' replication. As compared to baseline, the percentage of $\mathrm{M}^{3} 0^{+}$ cells was not significantly different at study end in the exenatide group but was significantly increased in the saline-treated control group (Figure 4B), indicating decreased apoptosis in the islets of baboons who received exenatide compared with saline. After exenatide treatment, the percentage of islet cells staining positive for the transdifferentiation marker c-KIT was significantly increased compared with baseline ( $P=$ $0.01)$, and it was significantly higher than in saline-treated baboons $(P=0.01)$ (Figure $4 \mathrm{C}$, Supplemental Figure $6 \mathrm{C}$ ). Immunofluorescence demonstrated the presence of cells staining positive for both c-KIT and insulin (Supplemental Figure 9), documenting that islet $\beta$ cells were among the cells undergoing transdifferentiation in the exenatide group. Colocalization of insulin and somatostatin was not observed before or after treatment with either exenatide or saline (Supplemental Figure 10). 
Table 2. Discordant effects of exenatide or saline treatments on the $\beta$ cell function adjusted for the corresponding $\beta$ cell volume

\begin{tabular}{|c|c|c|c|c|c|c|}
\hline & $\begin{array}{l}\text { Exenatide } \\
\text { (baseline) }\end{array}$ & $\begin{array}{l}\text { Exenatide } \\
\text { (study end) }\end{array}$ & $\Delta$ vs. baseline & Saline (baseline) & Saline (study end) & $\Delta$ vs. baseline \\
\hline Insulin secretion (AUC) & 29,243 & 16,910 & $-43 \%$ & 16,399 & 16,862 & $+2 \%$ \\
\hline$\beta$ cell volume (\%) & 5.6 & 4.7 & $-17 \%$ & 5.5 & 3.12 & $-44 \%$ \\
\hline $\begin{array}{l}\text { Insulin secretion (AUC)/ } \beta \\
\text { cell volume (\%) }\end{array}$ & 5230 & 3597 & $-32 \%$ & 2981 & 5404 & $+81 \%$ \\
\hline
\end{tabular}

Exenatide resulted in islet cell ultrastructural changes consistent with protection from cellular stress and secretory dysfunction. Electron microscopy was undertaken to visualize islet cell ultrastructure and $\beta$ cell secretory granule morphology and composition before and after treatment in the exenatide and saline groups (Figure 5 and Supplemental Figure 11). At baseline, both $\alpha$ and $\beta$ cells were normal in appearance and well granulated in both groups. However, in partially pancreatectomized baboons receiving saline, the appearance of degenerative features, including pycnotic nuclei and darkened cytoplasm, indicative of apoptosis, was observed in both $\alpha$ and $\beta$ cells. Poorly granulated $\beta$ cells also were present in the saline-treated group (Figure 5 and Supplemental Figure 11). In contrast, normal cellular ultrastructure with well-granulated $\beta$ cells was preserved after PPx in the exenatide-treated group (Figure 5 and Supplemental Figure 11). Further assessment of insulin secretory granules revealed that, after treatment with exenatide, the pancreata of baboons had fewer large, electron-clear progranules $(P=0.03)$ and more electron-dense mature granules $(P=0.01)$ relative to the saline control group (Figure 6, A-D). The amount of total granules was unchanged by exenatide but was increased after saline $(P=0.01)$ because of an increased number of progranules (Figure $6 \mathrm{E}$ ).

Immunogold labeling with electron microscopy provided further support for normal $\beta$ cell secretory function following exenatide treatment (Figure 7). The number of proinsulin-labeled granules was greater in the saline-treated group compared with the exenatide-treated baboons (Figure 7, A-D). Insulin appearance inside the granules remained unchanged from baseline to the end of the study in the exenatide group (Figure 7, C and D). Consistent with these findings, the plasma proinsulin concentration during the hyperglycemic clamp was significantly lower after exenatide treatment (Supplemental Figure 12).

In the saline-treated group $\beta$ cells had morphological changes consistent with endoplasmic reticulum and mitochondrial stress (Figure 8). Specifically, in the saline-treated group mitochondrial cristae were disordered, and endoplasmic reticulum and Golgi membranes showed features of degeneration (Figure $8 \mathrm{~B}$ ); such changes in mitochondrial, endoplasmic reticulum, and Golgi structure were not found in the exenatide-treated group (Figure 8D). Collectively, the electron microscopic findings are consistent with a phenotype of whole-islet and $\beta$ cell stress and are consistent with the functional defect in insulin secretion induced by PPx. In contrast, the islets of exenatide-treated animals were protected from these structural and functional abnormalities.

\section{Discussion}

GLP-1 RAs improve glucose control through several and, as of yet, not completely understood mechanisms, including glucose-dependent enhancement of insulin secretion and inhibition of glucagon release $(16-19,33)$.

We report the first direct evidence, we believe, in a nonrodent species for enhanced $\beta$ cell replication and decreased $\beta$ cell apoptosis and cellular stress following chronic exenatide administration. Because the genetic background of baboons closely resembles that of humans, this observation raises the possibility that GLP-1 RA can stimulate $\beta$ cell proliferation in humans if a sufficiently high plasma GLP-1 RA concentration can be achieved. We also observed an increase in whole-body insulin sensitivity after exenatide treatment in association with a compensatory decrease in insulin secretion. Notably, the disposition index increased following exenatide treatment, indicating that intrinsic $\beta$ cell secretory function was enhanced by exenatide treatment in face of increased insulin sensitivity. Further, the percentage increase in the disposition index was greater than the percentage increase in $\beta$ cell volume (an indirect measure of $\beta$ cell mass), indicating that exenatide exerts independent actions both to stimulate $\beta$ cell proliferation and to augment $\beta$ cell function.

The partially pancreatectomized baboon model was designed, based on the partially pancreatectomized rat (34), to generate a robust translational model of early-stage $\beta$ cell loss with emerging features of cellular stress, secretory dysregulation, and islet cell apoptosis. We believe that this goal was achieved because 13 
A

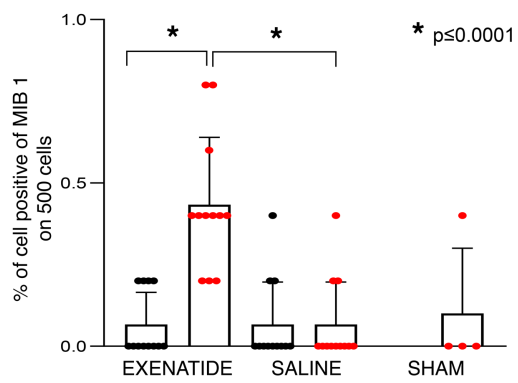

B

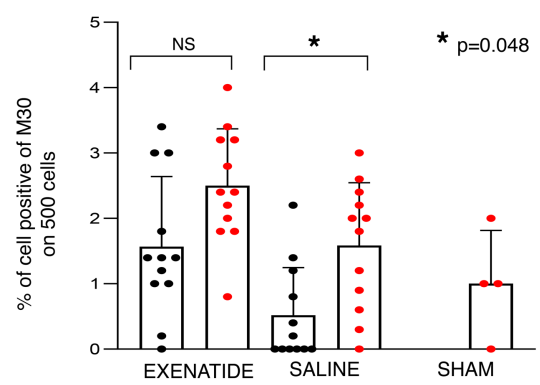

C

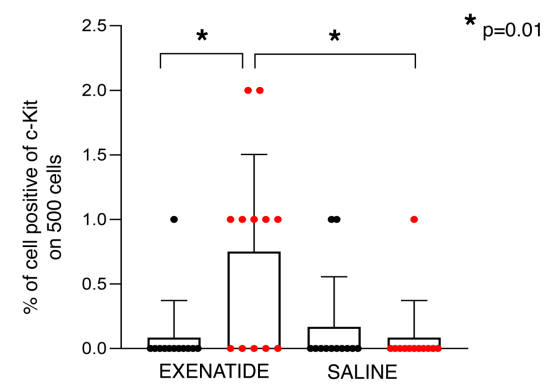

Figure 4. Effect of exenatide on islet cell replication and apoptosis. (A) The percentage of the islet cells positive for the replication marker Ki-67 nuclear protein (antibody MIB-1) before (black) and after the treatments (red). (B) The percentage of the islet cells positive for the apoptosis marker M30 before (black) and after (red) treatment. (C) The percentage of islet cells positive for the hematopoietic stem cell marker c-KIT before (black) and after (red) treatment with exenatide or saline. Number of sections for each baboon: 4 ( 2 sections at baseline and 2 sections at the end of the study). Comparisons between baseline and after-treatment data for each study group were performed by Wilcoxon's test. A general linear model for multiple comparisons adjusted for age and body weight was used to test differences between exenatide- and saline-treated animals.

weeks after PPx, baboon islets and $\beta$ cells showed morphological features of cellular stress and secretory granule dysregulation with increased proinsulin concentrations, all consistent with emerging insulin secretory dysfunction. Of note, the mean relative $\beta$ cell volume was reduced by $43 \%$ in the saline-treated group, which is consistent with the $\beta$ cell deficit Butler et al. reported in humans with impaired fasting glucose (4).

Morphometric analysis of pancreatic sections obtained before and after treatment supported the beneficial and protective effect of exenatide on whole-islet volume. Relative volumes of all islet cell types, and in particular $\beta$ cells, were preserved after exenatide treatment, while islet cell volumes were reduced in the saline-treated control group. When the difference in islet cell volumes in the different regions of the baboon pancreas are taken into account (i.e., lower in the tail compared with the head-body), it is clear that treatment with exenatide increased islet $\beta, \alpha$, and $\delta$ cell volumes. This is supported by the finding that the volumes of all 3 islet cell types were similar, or even higher, in the head-body of exenatide-treated baboons than in the tail of anatomic controls. The increased islet cell volumes after exenatide treatment are due to increased cell replication and reduced cell apoptosis as demonstrated by Ki67 and M30 immunostainings, respectively. Islet volume depends on the balance between islet cell proliferation and apoptosis. As demonstrated in the present study, exenatide promotes islet cell proliferation, while simultaneously reducing apoptosis as compared with saline treatment. In particular, we found that exenatide treatment induced a 5-fold increase in islet cells' replication as indicated by Ki67 immunostaining. In comparison with baseline, the number of islet cells undergoing apoptosis was 1.6-fold increased in exenatide-treated baboons, although not significantly; in contrast, it was increased by 3.4-fold in saline-treated animals. From the quantitative standpoint a 5-fold increase in replication coupled with a 1.6-fold increase in apoptosis, with a starting islet cell volume of $3.2 \%$ of total pancreas, would be expected to produce an expansion of approximately 2-fold of islet cell volume over 13 weeks. Drugs affecting islet cells' proliferation and apoptosis are well known, but they have been studied mainly in rodent models (35-38) and never in nonhuman primates or humans. Recently, liraglutide, a human GLP-1 analog, was shown to increase islet mass by stimulating $\beta$ cell proliferation and reducing $\beta$ cell apoptosis by enhancing nephrin expression, a protein involved in $\beta$ cell survival signaling, and by stimulating PI3K-dependent Akt phosphorylation (39). Conversely, in the study by Bunck et al. (19), 52 weeks of exenatide treatment did not exert any proliferative effect on $\beta$ cell mass because within weeks of discontinuing exenatide therapy in patients with $\mathrm{T} 2 \mathrm{D}$, insulin secretion declined to pretreatment level. However, after 3 years of treatment, exenatide resulted in increased insulin sensitivity along with improved $\beta$ cell function that were sustained after cessation of treatment for 4 weeks (40). Our results, although generated in partially pancreatectomized baboons treated with continuous IV exenatide administration, which could have induced a certain degree of GLP-1 receptor desensitization, are consistent with those of Bunck et al. (40). Notably, at study end serum exenatide levels were higher $(758 \pm 162 \mathrm{pg} / \mathrm{mL})$ in the exenatide group compared with the saline group $(0.0$ $\mathrm{pg} / \mathrm{mL}$ ) and 4-fold higher than those achieved in diabetic patients treated with exenatide (41). Thus, our results raise the intriguing possibility that if the plasma exenatide concentration can be raised sufficiently high, it might be possible to stimulate $\beta$ cell proliferation and increase $\beta$ cell mass. 
BASAL
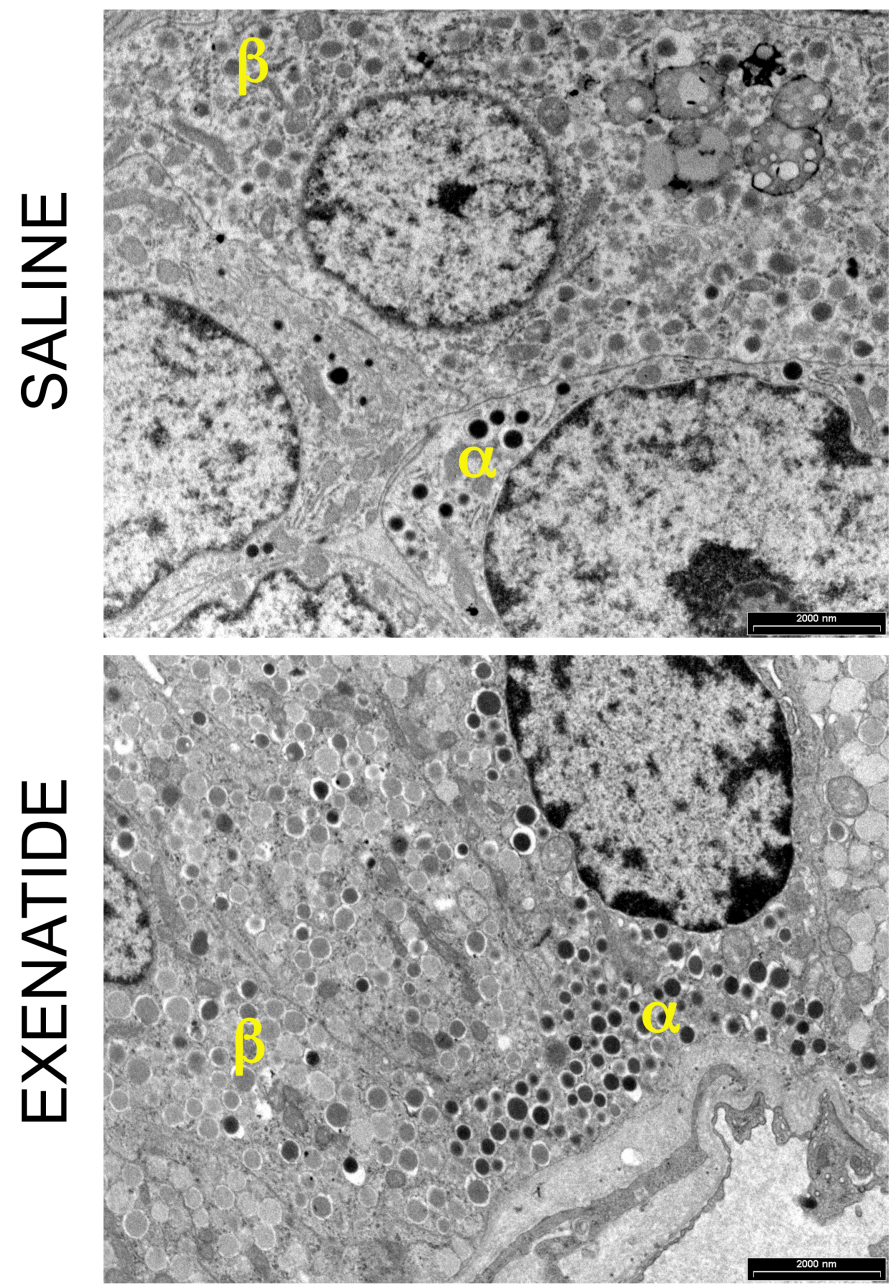

END OF THE STUDY
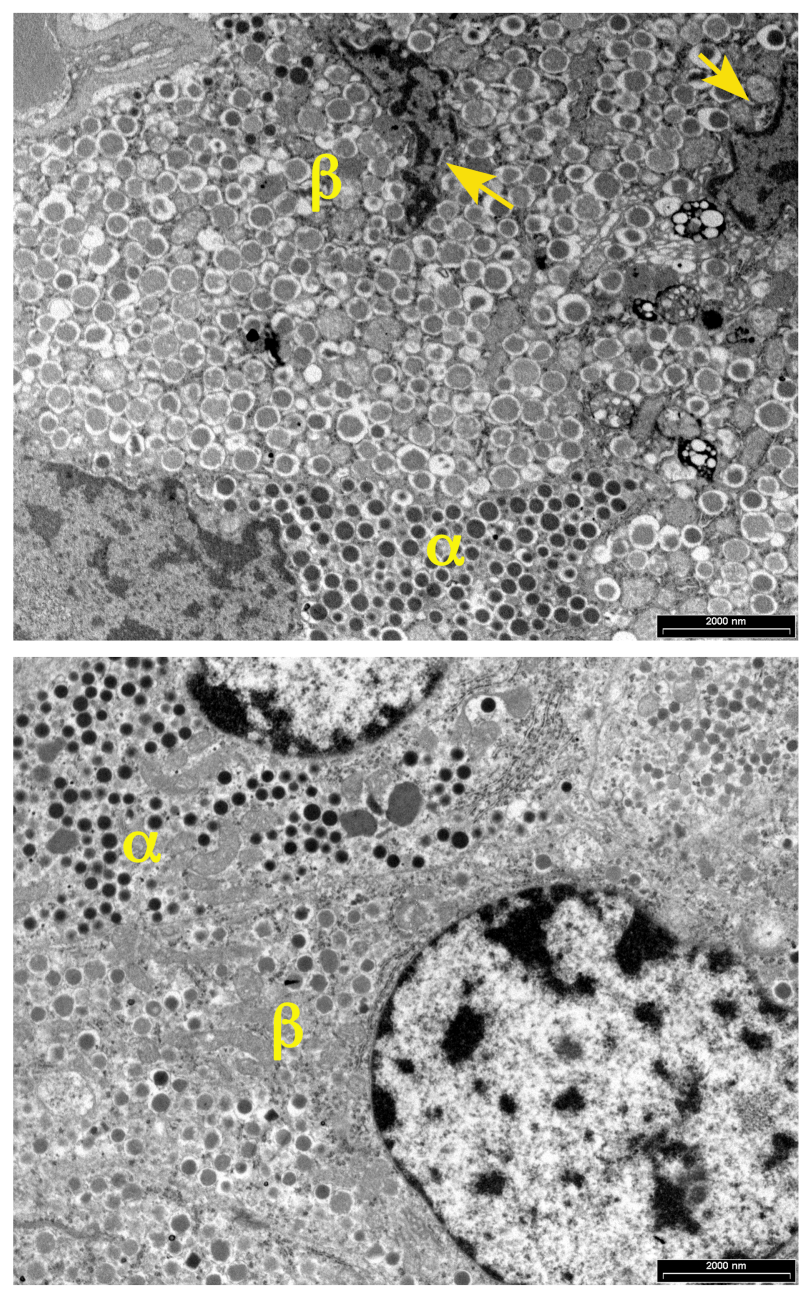

Figure 5. Representative figure of electron microscopy of pancreatic specimens taken before and after treatment with exenatide or saline. At baseline both $\beta$ and $\alpha$ cells appeared healthy and well granulated. After exenatide treatment $\beta$ and $\alpha$ cells continued to appear healthy and well granulated. Conversely, after treatment with saline, both cell types showed degenerative features, including pycnotic nuclei (arrows) and dark cytoplasm, indicative of ongoing apoptosis and poorly granulated $\beta$ cells. Scale bar: $2000 \mathrm{~nm}$.

After exenatide treatment we also detected a significant number of cells that stained positive for the stem cell marker c-KIT $(P=0.01)$, which has been shown to be involved in islet development and $\beta$ cell proliferation, maturation, and survival $(42,43) . \mathrm{c}-\mathrm{KIT}^{+}$cells were demonstrated both in islets and in ducts, and a fraction of them costained for insulin. Conversely, c-KIT ${ }^{+}$cells were absent in all groups before treatment and were absent after treatment in the saline-treated group. These findings are in agreement with those described in a previously published study, in which we observed c-KIT ${ }^{+}$cells coexpressing insulin in pancreatic ducts of baboons treated with exenatide (31). However, the absence of cells costaining for insulin and somatostatin, as observed in states of stimulated $\beta$ cell neogenesis, suggests that increased replication, rather than neogenesis, accounts for exenatide-stimulated $\beta$ cell growth in the present study.

Safety concerns have emerged about the potential proliferative effects of exenatide and other GLP1 RAs, although causal evidence for a link between exenatide and pancreatic cancer is lacking. We recently reported that chronic infusion of exenatide for 14 weeks did not induce pancreatitis, parenchymal or periductal inflammatory cell accumulation, ductal hyperplasia, or dysplastic lesions/pancreatic intraepithelial neoplasia in baboons (31). Similarly, in the present study no inflammatory or neoplastic changes were observed, and there was no increase in plasma amylase concentration in exenatide-treated baboons. Importantly, although serum exenatide levels were markedly increased at the end of the study, no side effects, including vomiting and anorexia, were observed in exenatide-treated animals. 


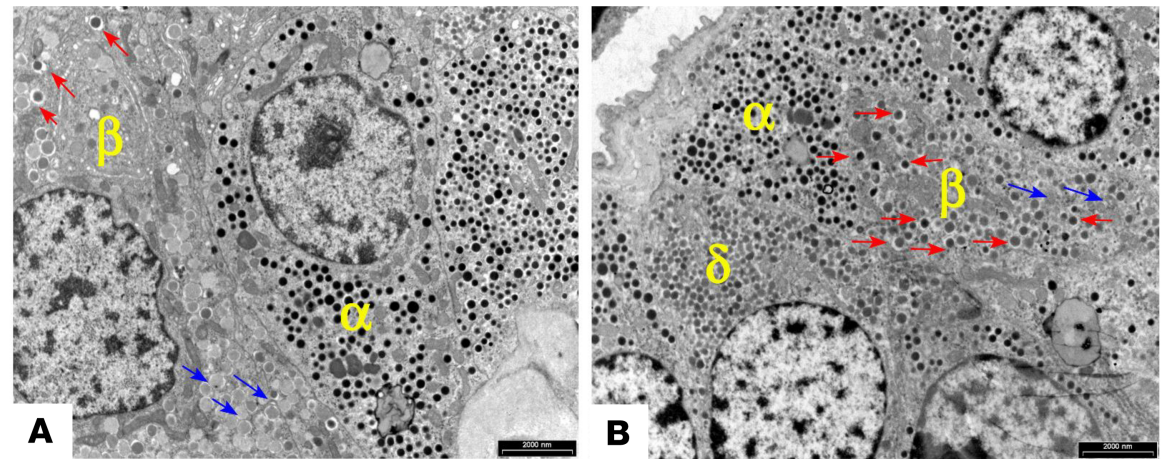

C

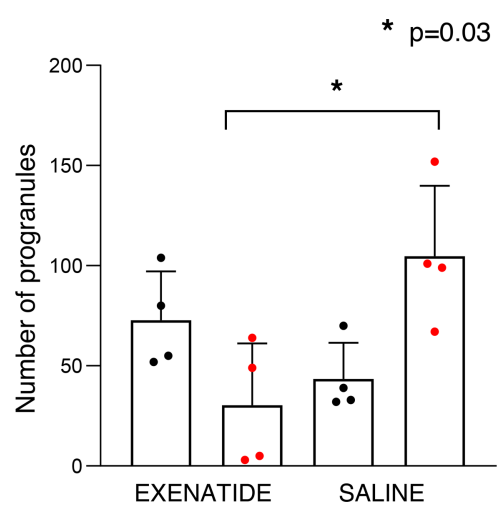

D

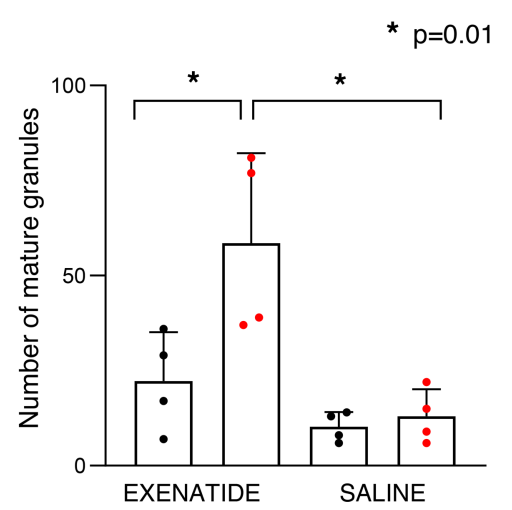

E

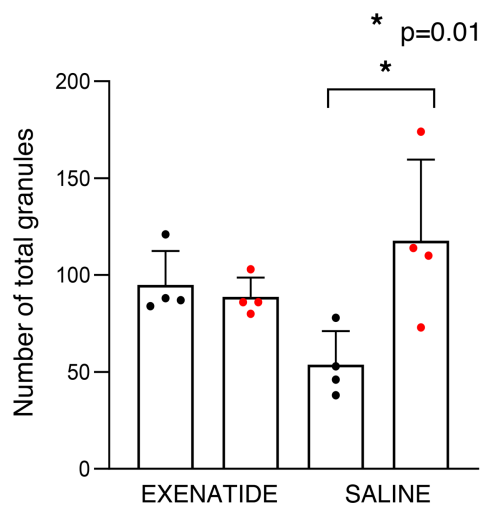

Figure 6. Effect of exenatide on the maturation process of insulin granules. (A) Baboon pancreatic $\beta$ cell contains classic, electron-dense, mature insulin granules (indicated by red arrows) as well as immature larger and electron-clear (indicated by blue arrows) insulin containing progranules. (B) After PPx and in vivo exenatide treatment, a decrease in immature granules and an increase in the number of mature granules were observed. Mean values from (C) quantitation of insulin progranules and (D) mature insulin granules and (E) total number of granules (progranules + mature granules) before (black) and after (red) exenatide and saline treatment in the pancreas of nonhuman primates. Number of baboons: 4 at baseline and 4 after treatment for both groups. Comparisons between baseline and after-treatment data for each study group were performed by Wilcoxon's test. A general linear model for multiple comparisons adjusted for age and body weight was used to test differences between exenatide- versus saline-treated animals. ${ }^{*} P \leq 0.01$. Scale bar: $2000 \mathrm{~nm}$.

During the repeat hyperglycemic clamp at study end, exenatide-treated baboons had lower insulin secretory responses to both glucose and L-arginine compared with the basal, pretreatment hyperglycemic clamp study. The decrease in insulin secretion most likely was attributable to the concomitant increase in insulin sensitivity. However, when insulin secretion was related to the degree of insulin resistance (disposition index), exenatide treatment resulted in a significant, almost 2 -fold increase in $\beta$ cell function. This observation is consistent with prior studies with exenatide in humans (44). Recent studies by us $(45,46)$ support an insulin-sensitizing effect of exenatide in both muscle and liver. Accordingly, we have reported that GLP-1 receptor protein is expressed in the skeletal muscle and liver of baboons, and it also is present in human skeletal muscle (45). Other studies also suggest that exenatide improves insulin sensitivity, independent of changes in body weight (47-49). In the present study, treatment with exenatide did not change total body weight or lean body mass. Although total body fat mass declined in exenatide-treated baboons, a similar decrease was observed in saline-treated animals in whom insulin sensitivity did not increase. Because the suppression of plasma glucagon during the hyperglycemic clamp was similar in all groups, differences in plasma glucagon concentration cannot explain the increase in insulin sensitivity in the exenatide-treated group. Therefore, the increase in insulin sensitivity observed after exenatide treatment most likely was due to a direct insulin-sensitizing effect. Levels of phosphorylated Akt (p-Akt) Ser ${ }^{473}$ increased significantly $(P=$ 0.03 ) in skeletal muscle of exenatide-treated baboons compared with baseline and with saline-treated controls and could, at least in part, play a role in the increase in insulin sensitivity. No significant changes were observed in any other mediators of insulin action in muscle. In the liver, among the measured mediators of insulin action, the only change that we found was a decrease in ERK phosphorylation, which is not a typical mediator of insulin's effect on glucose metabolism. Therefore, it is unlikely that the insulin-sensitiz- 

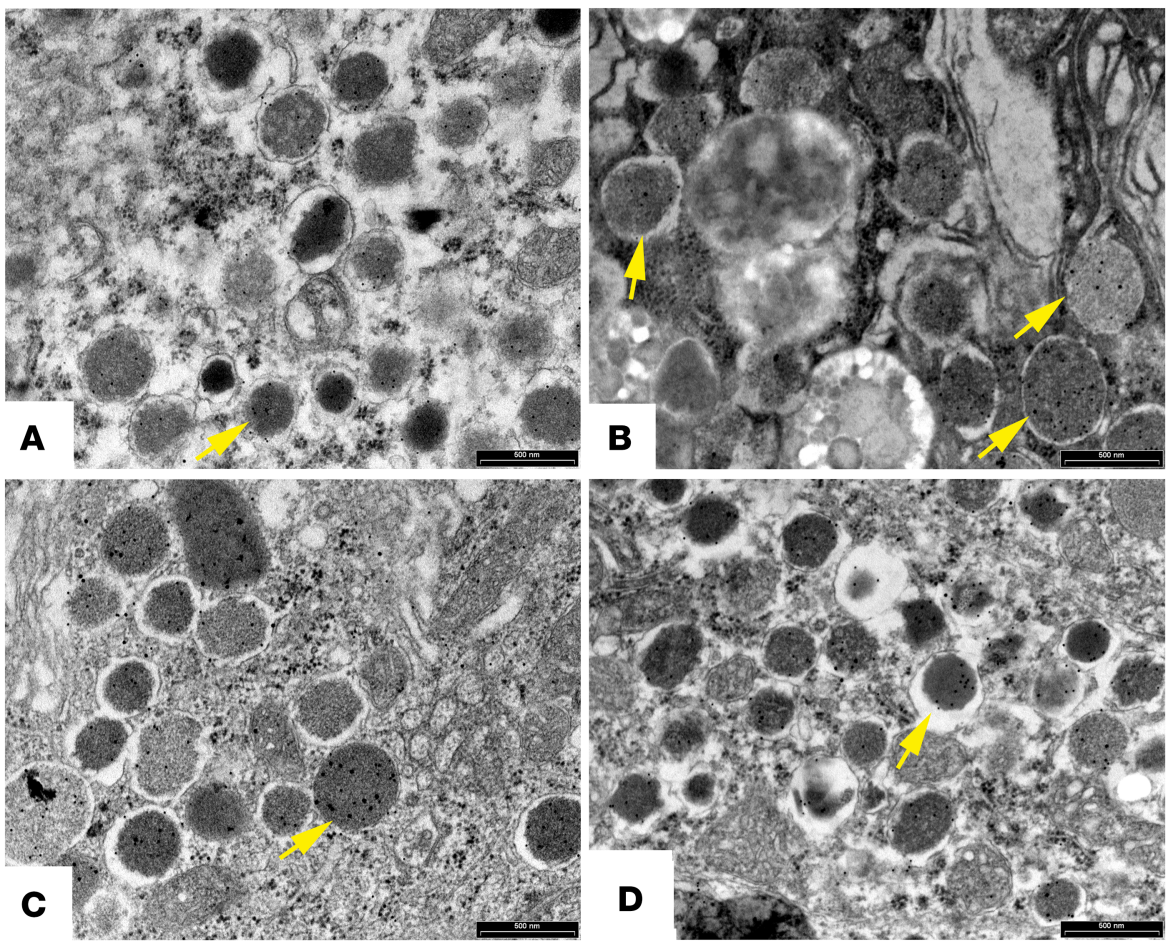

Figure 7. Effect of exenatide on proinsulin and insulin secretory granules. Electron microscopy of pancreatic specimens before (A and $\mathbf{C}$ ) and after in vivo treatment with saline (B) or exenatide (D). Images show immunogold labeling for the presence of insulin-containing $(12 \mathrm{~nm})$ and proinsulin-containing $(18 \mathrm{~nm})$ secretory granules. Proinsulin-labeled granules (arrows) were more numerous in the saline-treated (B) than in the exenatide-treated animals (D).Scale bar: $500 \mathrm{~nm}$.

ing effect of exenatide can be attributed to an increase in insulin signal transduction, which suggests that exenatide may exert its insulin-sensitizing effect on postreceptor postsignaling intracellular pathways. Consistent with this, we recently demonstrated that exenatide activates glucose transport by an AMP-activated protein kinase-dependent mechanism in vitro (45).

Electron microscopy (EM) showed that the $\beta$ cells of exenatide-treated baboons were healthy and replenished with mature insulin granules, as evidenced by the typical presence of high-electron density, precipitated, crystalline insulin. In contrast, the $\beta$ cells of saline-treated controls showed signs of distress, including condensed pycnotic nuclei and pale, immature granules, indicative of accelerated insulin secretion, $\beta$ cell stress, and emerging $\beta$ cell exhaustion. These ultrastructural findings are consistent with the increased number of apoptotic cells found in the islets of saline-treated baboons. This improved histological picture of $\beta$ cell health can be explained by one or both of the following mechanisms: (a) a direct effect of exenatide on the $\beta$ cell to reduce stress and apoptosis and (b) an unloading of the $\beta$ cell with reduction in insulin secretion secondary to the improvement in insulin sensitivity. Thus, exenatide treatment reduced insulin secretion by $32 \%$, whereas treatment with saline resulted in an $81 \%$ increase compared with the basal pretreatment value. This is of importance because $\beta$ cell rest diminishes $\beta$ cell immunogenicity (49) and renders $\beta$ cells less vulnerable to cytotoxic insults (50-52).

Research trials and clinical practice have shown that treatment with exenatide causes body weight and fat mass reduction (16-19) secondary to decreased energy intake (53). However, it has been hypothesized that GLP-1 RAs also might be involved in the regulation of energy metabolism (54-56). Although we found a significant decrease in fat mass in exenatide-treated baboons, a similar decrease in fat mas was observed in the saline-treated groups at study end. Lean mass and body weight were slightly decreased after saline treatment; similarly, a small but insignificant decrease in lean mass and body weight was found in the exenatide group. Overall, these variations in body composition are modest in both study groups and may be the consequence of surgery and long-term catheterization rather than an effect of exenatide or saline treatment. Food intake did not differ between exenatide-treated and saline-treated baboons, indicating that the dose of exenatide used in the present study did not alter energy intake. 

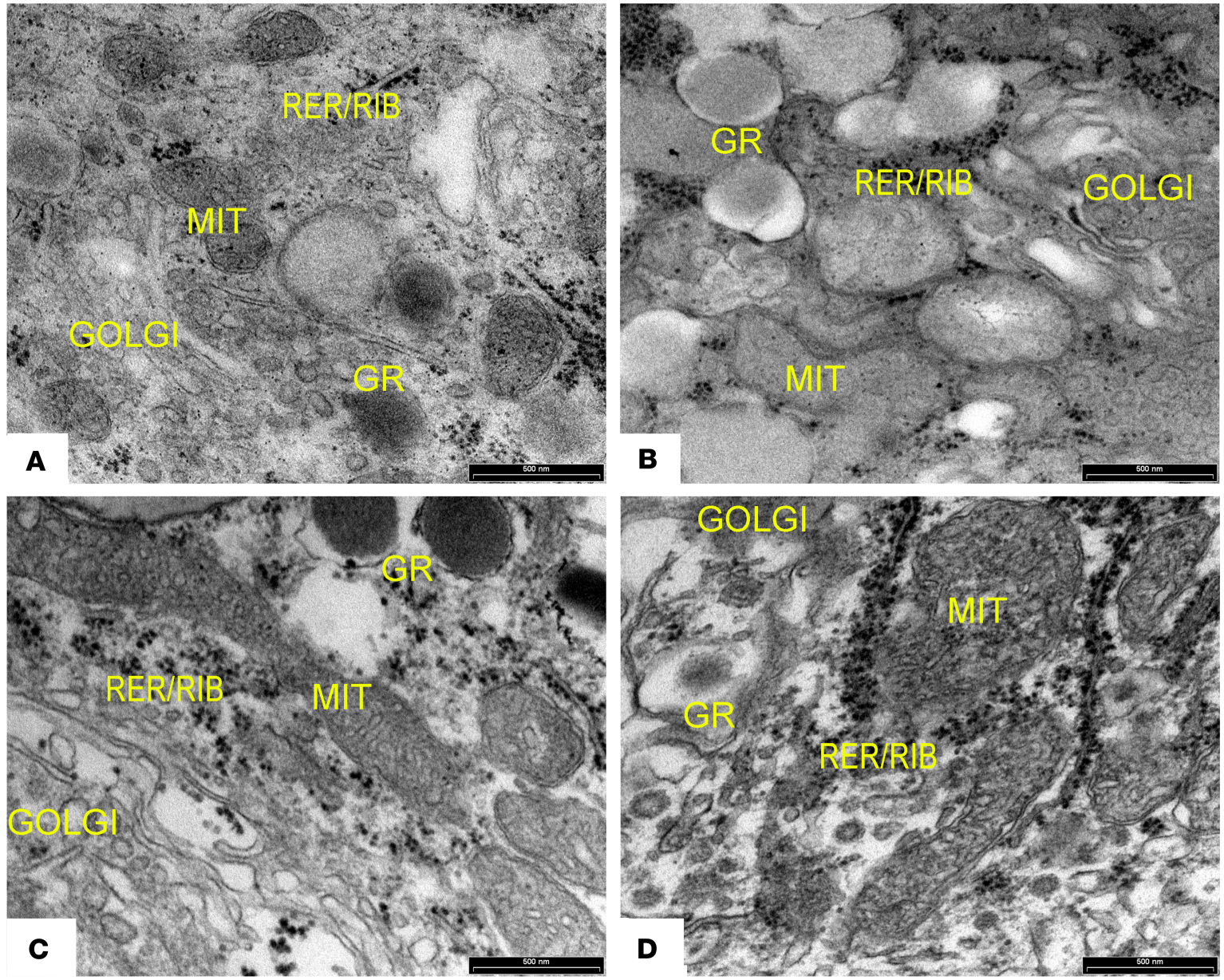

Figure 8. Exenatide resulted in islet cell ultrastructural changes consistent with protection from cellular stress. Electron microscopy of pancreatic specimens taken before (A and $\mathbf{C}$ ) and after treatment with saline (B) or exenatide (D) showing organelle features in islet cells. At the end of the study in the saline-treated group, mitochondrial cristae were disordered, and endoplasmic reticulum and Golgi membranes showed features of degeneration; such changes in mitochondrial, endoplasmic reticulum, and Golgi structure were absent in the exenatide-treated group. MIT: mitochondria; GR: granules; RER/ RIB: rough endoplasmic reticulum/ribosomes. Scale bar: $500 \mathrm{~nm}$.

A number of limitations should be considered when interpreting our results. First, we studied only female baboons. Although this methodological approach, which commonly is used in animal-based studies, makes the results more homogeneous, whether our results can be generalized to male primates needs to be established. Second, we did not measure energy expenditure; therefore, we cannot firmly establish that exenatide does not affect energy expenditure. However, the observation that body weight and food consumption were stable during the study period in the 2 experimental groups does not support a significant change in energy expenditure. We did not observe significant differences in fasting plasma glucose and $\mathrm{HbA1c}$ levels between exenatide, saline, or SHAM groups, indicating that baboons in the 3 study groups did not develop diabetes. This most likely is explained by the surgical PPx, which removed only a relatively small portion of the pancreas (about one-third of the pancreas), which was followed by a compensatory increase in insulin secretion by the remaining pancreas. However, we have no data regarding postprandial glucose levels. Although we cannot exclude the possibility that there were differences in postprandial glucose levels between saline- and exenatide-treated animals, we think that this is unlikely because the $\mathrm{HbA1c}$, as well as the fasting glucose, was similar in the 2 experimental groups.

In conclusion, chronic intravenous exenatide administration causes (a) an approximately 2-fold increase in $\beta$ cell function; (b) a significant increase in $\beta$ cell volume, which results primarily from an increase in $\beta$ cell proliferation; (c) a major improvement in $\beta$ cell health and reduced $\beta$ cell stress as demonstrated by routine and EM histology; and (d) an improvement in total body insulin sensitivity. This study provides solid grounds for further studies aimed at exploring GLP1 RAs' capability to preserve $\beta$ cell mass in patients with diabetes and in subjects at high risk of developing diabetes and for investigating in more detail the pharmacodynamics of antidiabetic drugs, including GLP1 RAs, in baboons. 


\section{Methods}

Study population. Twenty-eight female, nondiabetic baboons (Papio hamadryas sp.) aged $13 \pm 3$ years were randomly selected from the colony of the Southwest National Primate Research Center at Texas Biomedical Research Institute (San Antonio, Texas, USA) using previously published criteria (26). Twenty-four animals underwent abdominal surgery to resect the tail of the pancreas (PPx) and then were randomized to receive an intravenous infusion of saline $(n=12$; age $=12 \pm 2$ years $)$ or exenatide $(n=12$; age $=13 \pm 3$ years) for 13 weeks. Four animals underwent sham abdominal surgery without PPx followed by a chronic saline intravenous infusion (SHAM; $n=4$; age $=13 \pm 2$ years) for 13 weeks.

Each animal was housed in a single cage with ad libitum access to water and food. The amount of food consumed by each animal was registered daily. Experimental protocols were approved by the Institutional Animal Care and Use Committee (IACUC) of the Texas Biomedical Research Institute and the University of Texas Health Science Center at San Antonio.

Before treatment baboons underwent a body composition analysis and long-term catheterization for blood collection and drug infusion by placing heparin-coated polyurethane catheters (SoloCath catheters, Harvard Apparatus, Holliston, Massachusetts, USA) in the internal jugular vein and carotid artery. Catheters were routed subcutaneously to the midscapular region, where they were connected to the tether jacket chronic infusion system $(31,57)$. Three days after catheterization (i.e., before abdominal surgery), a 2-step hyperglycemic clamp with arginine (10\% arginine hydrochloride, Hospira, Pfizer, Lake Forest, Illinois, USA) stimulation was performed. Within 3 to 5 days after the hyperglycemic clamp, abdominal surgery was performed as described below and total parenteral nutrition was started. After a 96-hour recovery period, baboons were fed again with standard chow and were chronically infused $(24 \mathrm{~h} / \mathrm{d})$ for 13 weeks with either normal saline or exenatide (Byetta, Amylin Pharmaceuticals, San Diego, California, USA) diluted in normal saline at the rate of $0.014 \mu \mathrm{g} / \mathrm{kg} / \mathrm{h}$, as previously described (31). At the end of the 13-week treatment period, following a 72-hour washout period, baboons underwent a second body composition analysis and a 2-step hyperglycemic clamp with arginine stimulation. Baboons were then euthanized and the whole pancreas from the SHAM group and the remnant pancreas (head-body) from the other 2 groups was harvested.

An additional group of 16 baboons ( 8 males, 8 females) was studied as controls for pancreatic anatomy. Their whole pancreata were removed at necropsy to determine the difference in islet histology and islet cell volumes in the tail versus head-body of the pancreas.

Body composition analysis. Baboons underwent a dual-energy x-ray absorptiometry scan (Lunar Prodigy Whole Body Scanner; GE Medical Systems, Madison, Wisconsin, USA) to determine fat-free mass, fat mass, percentage body fat, and bone mineral content. Scanning was performed on ketamine-sedated animals, and data were analyzed using the software Encore2007 (GE Healthcare, Madison, Wisconsin, USA).

Hyperglycemic clamp. After a 10- to 12-hour overnight fast, baboons were sedated and intubated endotracheally under direct laryngoscopic visualization. Deep anesthesia was induced using a mix of oxygen and inhaled isofluorane $(1.5 \% v / v)$. After $60-90$ minutes to allow animal stabilization, a 2-step hyperglycemic clamp with arginine stimulation was performed (58). From 0-90 minutes the plasma glucose concentration was raised by $100 \mathrm{mg} / \mathrm{dL}$ (i.e., from $\sim 90$ to $190 \mathrm{mg} / \mathrm{dL}$ ), and from $90-180$ minutes the plasma glucose concentration was raised by an additional $100 \mathrm{mg} / \mathrm{dL}$ (i.e., from 190 to $290 \mathrm{mg} / \mathrm{dL}$ ). At 180 minutes animals received a bolus ( $0.5 \mathrm{~g} / \mathrm{kg}$ of body weight) injection of arginine, and the animals were followed for an additional 30 minutes. Plasma glucose concentration was measured every 2 minutes from 0-10, 90-100, and 180-190 minutes and every 5-10 minutes from 10-90, 100-180, and 190-220 minutes. Glucose was measured by using a glucose analyzer (GM9 Glucose Analyzer, Analox Instruments, Lunenburg, Massachusetts, USA) and insulin, glucagon, and C-peptide by radioimmunoassay (27). The following parameters were computed: (a) AUC for insulin and C-peptide concentration (0-210 minutes) was calculated by using the trapezoidal rule; (b) ISR was calculated from deconvolution of the plasma C-peptide concentration (59); (c) hepatic insulin clearance was computed as ISR/plasma insulin concentration during the hyperglycemic clamp (60); (d) insulin sensitivity was assessed by the M/I index (61), where the $M$ value is the whole-body glucose disposal rate calculated from the glucose infusion rate during the last 30 minutes of the hyperglycemic clamp (150-180 minutes), corrected by the changes in glucose pool, divided by the mean plasma insulin concentration during the same period; and (e) $\beta$ cell function was estimated by the so-called disposition index, calculated by multiplying the ISR by insulin sensitivity measured by M/I (3).

$P P x$. PPx was performed under general anesthesia with isofluorane $1.5 \% v / v$ as previously described (31) by making an incision on the mesoduodenum or omentum on each side of the pancreas to mark the 
portion to be removed. The pancreas then was ligated immediately proximal to the marks, and the distal part (tail), accounting for about $30 \%$ of the pancreas, was removed and collected for histological analysis before the start of treatment. Previous studies in primates and humans have shown that more than $50 \%$ of the pancreas mass must be excised to stimulate compensatory $\beta$ cell regeneration $(62,63)$. SHAM-operated baboons underwent a sham surgical procedure similar to that in the other 2 study groups without undergoing PPx. Following the surgery, intravenous parenteral nutrition with 5\% glucose solution, potassium, and amino acids was provided during a recovery period of 4 days along with antibiotics and analgesics. The perioperative/postoperative mortality was $0 \%$. Solid food was again introduced after the recovery period, and baboons were housed inside individual cages while on tether for treatment (31).

Western blots for insulin signaling. Skeletal muscle and liver samples were obtained following the second 2-step hyperglycemic clamp (i.e., after 13 weeks of exenatide or saline infusion) and frozen in liquid nitrogen. Western blot experiments were performed as described previously (64) using antibodies against IR- $\beta$ (Santa Cruz Biotechnology, Dallas, Texas, USA), IRS-1 (Thermo Fisher Scientific, Pittsburgh, Pennsylvania, USA), Akt and p-Akt (Ser473), ERK and p-ERK (Thr202/Tyr204), JNK and p-JNK (Thr183/ Tyr185), PTEN (Cell Signaling Technology, Beverly, Massachusetts, USA), and PHLPP1 (made in-house).

Histology, immunohistochemistry, and EM. Pancreatic specimens (tail and head-body portion) were fixed in $10 \%$ formalin solution and embedded in paraffin for histological and immunohistochemical analyses. Paraffin sections, $4 \mu \mathrm{m}$ thick, were stained for hematoxylin and eosin or processed by a Ventana Immunostainer (BenchMark-XT, Ventana Medical Systems, Inc., Tucson, Arizona, USA) for immunostaining for insulin (Insulin Cell Marque immuno-antibody, Ventana Medical Systems, Inc.), glucagon (Novocastra Glucagon antibody by Leica Microsystems, Inc., Bannoockburn, Illinois, USA), somatostatin (Somatostatin Cell Marque rabbit polyclonal antibody, Ventana Medical Systems, Inc.), and c-KIT (c-Kit rabbit polyclonal antibody, Cell Signaling Technology). Stained sections were then analyzed by CAST (Olympus 2.0 system, Olympus America Inc., Melville, New York, USA) to quantitate islet volume and relative islet $\beta, \alpha$, and $\delta$ cell volumes, using the stereology fundaments previously described on pancreatic sections randomly collected from the pancreas tail (basal) and head and body at the end of the study. The operator was blinded to the status of the baboon, and the reproducibility of the measurements was estimated twice in 5 specimens with a coefficient of variation less than $5 \%$. Each field of the slide was randomly selected using the CAST meander sampling. On average, we analyzed $125 \pm 46$ islets per animal per group on each slide, before and after treatment. Pancreas weight at baseline was $6.8 \pm 1.8 \mathrm{~g}$ vs. $6.4 \pm 1.8 \mathrm{~g}$ for the exenatide and saline groups, respectively $(P=0.788)$; at the end of the study, pancreas weight was $12.8 \pm 2.4$ vs. $14.5 \pm 3.9 \mathrm{~g}(P=0.271)$, respectively. Data obtained from CAST were expressed as percentage of total pancreas as previously described (30). Islet cell proliferation was measured by counting the number of Ki67-immunoreactive cells detected using the MIB-1 antibody (Dako, Carpinteria, California, USA). The number of apoptotic islet cells was evaluated using the monoclonal antibody M30 (Roche, Penzberg, Germany), which recognizes the caspase-cleaved, formalin-resistant epitope of cytokeratin 18.

For ultrastructural morphological analyses, pancreatic specimens of 4 saline-treated (before the start of saline treatment) and 4 exenatide-treated (before the start of exenatide treatment) baboons were fixed for 2 hours at $4^{\circ} \mathrm{C}$ in $2 \%$ paraformaldehyde and $2 \%$ glutaraldehyde in $0.05 \mathrm{M} \mathrm{pH} 7.3$ cacodylate buffer (Karnovsky fixative, EMS, Domat/Ems, Switzerland), postfixed in 1\% osmium tetroxide, and embedded in Epon-Araldyte (Honeywell-FLUKA, Seelze, Germany). For ultrastructural immunocytochemistry, thin sections were pretreated with sodium metaperiodate for 30 minutes, then placed onto a drop of ovalbumin for 5 minutes, transferred onto a drop of antiproinsulin (monoclonal mouse antiproinsulin, DSHB, Gentofte, Denmark), diluted 1:10 overnight, then after rinses transferred onto a drop of anti-insulin (polyclonal guinea pig anti-insulin, Dako, Glostrup, Denmark), diluted 1:50 overnight, and subsequently, after rinses, transferred onto a mixture of $18 \mathrm{~nm}$ colloidal gold-AffiniPure (Jackson ImmunoResearch, West Grove, Pennsylvania, USA) goat antimouse diluted 1:20 and of $12 \mathrm{~nm}$ colloidal gold-AffiniPure donkey antiguinea pig diluted 1:20. In control experiments the primary antibodies were omitted. All thin sections were counterstained with uranyl acetate and lead citrate and observed with a Morgagni Philips/Thermo Fisher Scientific electron microscope (FEI Company, Endovehn, the Netherlands).

For the evaluation of secretory, mature granules and progranules of $\beta$ cells, 4 cells for each group (before and after saline treatment and before and after exenatide treatment) were evaluated. The immunogold labelings were evaluated with a semiquantitative method. 
Immunofluorescence staining. Pancreatic sections, 3- $\mu \mathrm{m}$ thick, were fixed and immunostained as previously described $(31,65)$. The following antibodies were used: anti-insulin guinea pig monoclonal (Dako), anti-c-KIT mouse monoclonal antibody (Cell Signaling Technology), anti-KI67 rabbit polyclonal antibody (Cell Signaling Technology), and antisomatostatin mouse monoclonal antibody (Dako). Islets were imaged using a BioRad MRC 1024 confocal laser scanning microscope (BioRad, Hercules, California, USA). Confocal images were acquired sequentially, using the LaserSharp2000 software with a low iris diameter (66).

Controls for regional differences in islet cell volume. It is well established that there are significant differences between the number of islets in the tail versus head-body of the pancreas. To ensure accurate comparison of islet cell volumes before and after PPx (tail vs. head-body), we measured $\alpha, \beta$, and $\delta$ cell volumes in both the tail and head-body regions from whole, intact pancreases obtained from a representative sample of 16 randomly selected baboons that did not participate in the study.

Statistics. Data for continuous variables are given as the mean \pm SD. Given the small sample size (12 baboons in saline group, 12 in exenatide group, and 4 animals in SHAM group, $n=28$ ), nonparametric tests were carried out to analyze the data.

Differences in clinical data among the study groups were evaluated by using a general linear model with post hoc Fisher's least significant difference correction for pairwise comparisons.

To compare changes between baseline and end-of-study parameters in each study group, we used Wilcoxon's test. Statistical analyses were performed by using Stata/SE Version 11.2 (Stata Corp LP, College Station, Texas, USA). We considered a 2 -sided $P$ value no more than 0.05 statistically significant.

Study approval. Experimental protocols were approved by the IACUC of the Texas Biomedical Research Institute and the University of Texas Health Science Center at San Antonio.

\section{Author contributions}

TVF performed Western blot experiments, analyzed and interpreted the data, and wrote the manuscript; FC performed in vivo procedures, collected the data, and contributed to writing the manuscript; AMD designed the study and contributed to performing in vivo procedures and writing the manuscript; GF, SLR, AM, FS, CP, and ESDC performed immunohistochemical and EM analyses; PBH, GAA, RAB, AGC, $P$ Frost, EJD, and GAH performed pancreatic surgeries and oversaw baboons' recovery; RGM and AG contributed to analyzing the data; SK, AR, GD, AMP, FA, and AOC collected the data; P Fiorina and LL contributed to interpreting the data and to writing the discussion; RAD revised the manuscript and contributed to writing the discussion; and FF designed the study, contributed to performing in vivo procedures, interpreted the data, and wrote and revised the manuscript.

\section{Acknowledgments}

We thank Andrea Caumo, Department of Health Science, University of Milan, Italy, for his support in the analyses regarding relationship between insulin sensitivity and secretion in the 3 study groups at baseline and at the end of the study. This investigation was partially supported by NIH R01 DK080148 (to FF) and resources from the Southwest National Primate Research Center grant P51 OD011133 from the Office of Research Infrastructure Programs, NIH. TVF was supported in part by a fellowship from Fondazione Diabete Ricerca della SID, Italy. FF is grateful to Leslie David Hillis and Sylka Rodovalho for support throughout the course of the studies and preparation of the manuscript.FF is the guarantor of this work and, as such, had full access to all the data in the study and takes responsibility for the integrity of the data and the accuracy of the data analysis.

Address correspondence to: Franco Folli, Endocrinology and Metabolism, Department of Health Science, San Paolo Hospital, and ASST Santi Paolo e Carlo, Via A. di Rudini' 8, University of Milan, 20143 Milan, Italy. Phone: 39.02.50323192; Email: franco.folli@unimi.it or franco.folli@asst-santipaolocarlo.it.

1. Eisenbarth GS. Type I diabetes mellitus. A chronic autoimmune disease. N Engl J Med. 1986;314(21):1360-1368.

2. Weir GC, Bonner-Weir S. Five stages of evolving beta-cell dysfunction during progression to diabetes. Diabetes. 2004;53(Supp1 3):S16-S21.

3. Gastaldelli A, Ferrannini E, Miyazaki Y, Matsuda M, DeFronzo RA, San Antonio metabolism study. Beta-cell dysfunction and glucose intolerance: results from the San Antonio metabolism (SAM) study. Diabetologia. 2004;47(1):31-39.

4. Butler AE, Janson J, Bonner-Weir S, Ritzel R, Rizza RA, Butler PC. Beta-cell deficit and increased beta-cell apoptosis in humans with type 2 diabetes. Diabetes. 2003;52(1):102-110. 
5. Rahier J, Goebbels RM, Henquin JC. Cellular composition of the human diabetic pancreas. Diabetologia. 1983;24(5):366-371.

6. Matveyenko AV, Butler PC. Relationship between beta-cell mass and diabetes onset. Diabetes Obes Metab. 2008;10(Suppl 4):2331

7. Gianani R, et al. Dimorphic histopathology of long-standing childhood-onset diabetes. Diabetologia. 2010;53(4):690-698.

8. Arif S, et al. Blood and islet phenotypes indicate immunological heterogeneity in type 1 diabetes. Diabetes. 2014;63(11):38353845 .

9. Wang L, Lovejoy NF, Faustman DL. Persistence of prolonged C-peptide production in type 1 diabetes as measured with an ultrasensitive C-peptide assay. Diabetes Care. 2012;35(3):465-470.

10. UK Prospective Diabetes Study (UKPDS) Group. Intensive blood-glucose control with sulphonylureas or insulin compared with conventional treatment and risk of complications in patients with type 2 diabetes (UKPDS 33). Lancet. 1998;352(9131):837-853.

11. Turner RC, Cull CA, Frighi V, Holman RR. Glycemic control with diet, sulfonylurea, metformin, or insulin in patients with type 2 diabetes mellitus: progressive requirement for multiple therapies (UKPDS 49). UK Prospective Diabetes Study (UKPDS) Group. JAMA. 1999;281(21):2005-2012.

12. Wajchenberg BL. beta-cell failure in diabetes and preservation by clinical treatment. Endocr Rev. 2007;28(2):187-218.

13. Kahn SE, et al. Glycemic durability of rosiglitazone, metformin, or glyburide monotherapy. NEngl J Med. 2006;355(23):2427-2443.

14. Yki-Jarvinen H. ADOPT: lessons from comparison of glycemic durability of rosiglitazone, metformin, or glyburide monotherapy. Curr Diab Rep. 2007;7(3):173-174.

15. Maedler K, Carr RD, Bosco D, Zuellig RA, Berney T, Donath MY. Sulfonylurea induced beta-cell apoptosis in cultured human islets. J Clin Endocrinol Metab. 2005;90(1):501-506.

16. Shyangdan DS, Royle P, Clar C, Sharma P, Waugh N, Snaith A. Glucagon-like peptide analogues for type 2 diabetes mellitus. Cochrane Database Syst Rev. 2011;2011(10):CD006423.

17. Vilsbøll T, Christensen M, Junker AE, Knop FK, Gluud LL. Effects of glucagon-like peptide-1 receptor agonists on weight loss: systematic review and meta-analyses of randomised controlled trials. BMJ. 2012;344:d7771.

18. Campbell JE, Drucker DJ. Pharmacology, physiology, and mechanisms of incretin hormone action. Cell Metab. 2013;17(6):819-837.

19. Bunck MC, et al. One-year treatment with exenatide improves beta-cell function, compared with insulin glargine, in metformin-treated type 2 diabetic patients: a randomized, controlled trial. Diabetes Care. 2009;32(5):762-768.

20. Xu G, Stoffers DA, Habener JF, Bonner-Weir S. Exendin-4 stimulates both beta-cell replication and neogenesis, resulting in increased beta-cell mass and improved glucose tolerance in diabetic rats. Diabetes. 1999;48(12):2270-2276.

21. Xu G, Kaneto H, Lopez-Avalos MD, Weir GC, Bonner-Weir S. GLP-1/exendin-4 facilitates beta-cell neogenesis in rat and human pancreatic ducts. Diabetes Res Clin Pract. 2006;73(1):107-110.

22. Tian L, et al. Comparison of exendin-4 on beta-cell replication in mouse and human islet grafts. Transpl Int. 2011;24(8):856-864.

23. Toso C, et al. Liraglutide, a long-acting human glucagon-like peptide 1 analogue, improves human islet survival in culture. Transpl Int. 2010;23(3):259-265.

24. Cechin SR, et al. Anti-inflammatory properties of exenatide in human pancreatic islets. Cell Transplant. 2012;21(4):633-648.

25. Ferdaoussi M, et al. Exendin-4 protects beta-cells from interleukin-1 beta-induced apoptosis by interfering with the c-Jun NH2-terminal kinase pathway. Diabetes. 2008;57(5):1205-1215.

26. Kim JY, et al. Exendin-4 protects oxidative stress-induced $\beta$-cell apoptosis through reduced JNK and GSK3 $\beta$ activity. $J$ Korean Med Sci. 2010;25(11):1626-1632.

27. Chavez AO, et al. Physiological and molecular determinants of insulin action in the baboon. Diabetes. 2008;57(4):899-908

28. Higgins PB, et al. Eight week exposure to a high sugar high fat diet results in adiposity gain and alterations in metabolic biomarkers in baboons (Papio hamadryas sp.). Cardiovasc Diabetol. 2010;9:71.

29. Chavez AO, et al. Predictive models of insulin resistance derived from simple morphometric and biochemical indices related to obesity and the metabolic syndrome in baboons. Cardiovasc Diabetol. 2009;8:22.

30. Guardado-Mendoza R, et al. Pancreatic islet amyloidosis, beta-cell apoptosis, and alpha-cell proliferation are determinants of islet remodeling in type-2 diabetic baboons. Proc Natl Acad Sci USA. 2009;106(33):13992-13997.

31. Fiorentino TV, et al. Chronic continuous exenatide infusion does not cause pancreatic inflammation and ductal hyperplasia in non-human primates. Am J Pathol. 2015;185(1):139-150.

32. Cabrera O, Berman DM, Kenyon NS, Ricordi C, Berggren PO, Caicedo A. The unique cytoarchitecture of human pancreatic islets has implications for islet cell function. Proc Natl Acad Sci USA. 2006;103(7):2334-2339.

33. Zhang Y, et al. GLP-1 receptor in pancreatic $\alpha$-cells regulates glucagon secretion in a glucose-dependent bidirectional manner. Diabetes. 2019;68(1):34-44.

34. Rossetti L, Shulman GI, Zawalich W, DeFronzo RA. Effect of chronic hyperglycemia on in vivo insulin secretion in partially pancreatectomized rats. J Clin Invest. 1987;80(4):1037-1044.

35. Xu G, Stoffers DA, Habener JF, Bonner-Weir S. Exendin-4 stimulates both beta-cell replication and neogenesis, resulting in increased beta-cell mass and improved glucose tolerance in diabetic rats. Diabetes. 1999;48(12):2270-2276.

36. Farilla L, et al. Glucagon-like peptide-1 promotes islet cell growth and inhibits apoptosis in Zucker diabetic rats. Endocrinology. 2002;143(11):4397-4408.

37. Kawamori D, et al. GLP-1 signalling compensates for impaired insulin signalling in regulating beta cell proliferation in $\beta$ IRKO mice. Diabetologia. 2017;60(8):1442-1453.

38. Wiesmann UN, DiDonato S, Herschkowitz NN. Effect of chloroquine on cultured fibroblasts: release of lysosomal hydrolases and inhibition of their uptake. Biochem Biophys Res Commun. 1975;66(4):1338-1343.

39. Kapodistria K, Tsilibary EP, Kotsopoulou E, Moustardas P, Kitsiou P. Liraglutide, a human glucagon-like peptide-1 analog, stimulates AKT-dependent survival signalling and inhibits pancreatic $\beta$-cell apoptosis. J Cell Mol Med. 2018;22(6):2970-2980

40. Bunck MC, et al. Effects of exenatide on measures of $\beta$-cell function after 3 years in metformin-treated patients with type 2 diabetes. Diabetes Care. 2011;34(9):2041-2047.

41. Fineman MS, et al. Effect on glycemic control of exenatide (synthetic exendin-4) additive to existing metformin and/or sulfonylurea treatment in patients with type 2 diabetes. Diabetes Care. 2003;26(8):2370-2377. 
42. Li J, et al. Expression of c-Kit receptor tyrosine kinase and effect on beta-cell development in the human fetal pancreas. Am $J$ Physiol Endocrinol Metab. 2007;293(2):E475-E483.

43. Rachdi L, E1 Ghazi L, Bernex F, Panthier JJ, Czernichow P, Scharfmann R. Expression of the receptor tyrosine kinase KIT in mature beta-cells and in the pancreas in development. Diabetes. 2001;50(9):2021-2028.

44. van Raalte DH, et al. Exenatide improves $\beta$-cell function up to 3 years of treatment in patients with type 2 diabetes: a randomised controlled trial. Eur J Endocrinol. 2016;175(4):345-352.

45. Andreozzi F, et al. The GLP-1 receptor agonists exenatide and liraglutide activate glucose transport by an AMPK-dependent mechanism. J Transl Med. 2016;14(1):229.

46. Gastaldelli A, et al. Exenatide improves both hepatic and adipose tissue insulin resistance: A dynamic positron emission tomography study. Hepatology. 2016;64(6):2028-2037.

47. Zander M, Madsbad S, Madsen JL, Holst JJ. Effect of 6-week course of glucagon-like peptide 1 on glycaemic control, insulin sensitivity, and beta-cell function in type 2 diabetes: a parallel-group study. Lancet. 2002;359(9309):824-830.

48. Meneilly GS, Greig N, Tildesley H, Habener JF, Egan JM, Elahi D. Effects of 3 months of continuous subcutaneous administration of glucagon-like peptide 1 in elderly patients with type 2 diabetes. Diabetes Care. 2003;26(10):2835-2841.

49. Zheng D, Ionut V, Mooradian V, Stefanovski D, Bergman RN. Exenatide sensitizes insulin-mediated whole-body glucose disposal and promotes uptake of exogenous glucose by the liver. Diabetes. 2009;58(2):352-359.

50. Karlsson FA, Björk E. Beta-cell rest: a strategy for the prevention of autoimmune diabetes. Autoimmunity. 1997;26(2):117-122

51. Maedler K, et al. Glucose- and interleukin-1beta-induced beta-cell apoptosis requires Ca2+ influx and extracellular signal-regulated kinase (ERK) $1 / 2$ activation and is prevented by a sulfonylurea receptor 1/inwardly rectifying K+ channel 6.2 (SUR/ Kir6.2) selective potassium channel opener in human islets. Diabetes. 2004;53(7):1706-1713.

52. Ritzel RA, Jayasinghe S, Hansen JB, Sturis J, Langen R, Butler PC. Beta-cell selective K(ATP)-channel activation protects betacells and human islets from human islet amyloid polypeptide induced toxicity. Regul Pept. 2010;165(2-3):158-162.

53. Bradley DP, Kulstad R, Racine N, Shenker Y, Meredith M, Schoeller DA. Alterations in energy balance following exenatide administration. Appl Physiol Nutr Metab. 2012;37(5):893-899.

54. Beiroa D, et al. GLP-1 agonism stimulates brown adipose tissue thermogenesis and browning through hypothalamic AMPK. Diabetes. 2014;63(10):3346-3358.

55. Gupta NA, et al. The glucagon-like peptide-1 receptor agonist Exendin 4 has a protective role in ischemic injury of lean and steatotic liver by inhibiting cell death and stimulating lipolysis. Am J Pathol. 2012;181(5):1693-1701.

56. Ruiz-Grande C, Alarcón C, Mérida E, Valverde I. Lipolytic action of glucagon-like peptides in isolated rat adipocytes. Peptides. 1992;13(1):13-16.

57. Coelho AM, Carey KD. A social tethering system for nonhuman primates used in laboratory research. Lab Anim Sci. 1990;40(4):388-394

58. DeFronzo RA, Tobin JD, Andres R. Glucose clamp technique: a method for quantifying insulin secretion and resistance. Am J Physiol. 1979;237(3):E214-E223.

59. Van Cauter E, Mestrez F, Sturis J, Polonsky KS. Estimation of insulin secretion rates from C-peptide levels. Comparison of individual and standard kinetic parameters for C-peptide clearance. Diabetes. 1992;41(3):368-377

60. Ferrannini E, Gastaldelli A, Miyazaki Y, Matsuda M, Mari A, DeFronzo RA. Beta-Cell function in subjects spanning the range from normal glucose tolerance to overt diabetes: a new analysis. J Clin Endocrinol Metab. 2005;90(1):493-500.

61. Polonsky KS, et al. Quantitative study of insulin secretion and clearance in normal and obese subjects. J Clin Invest. $1988 ; 81(2): 435-441$

62. Kendall DM, Sutherland DE, Najarian JS, Goetz FC, Robertson RP. Effects of hemipancreatectomy on insulin secretion and glucose tolerance in healthy humans. NEngl J Med. 1990;322(13):898-903.

63. Matveyenko AV, Veldhuis JD, Butler PC. Mechanisms of impaired fasting glucose and glucose intolerance induced by an approximate 50\% pancreatectomy. Diabetes. 2006;55(8):2347-2356.

64. Monroy A, et al. Impaired regulation of the TNF-alpha converting enzyme/tissue inhibitor of metalloproteinase 3 proteolytic system in skeletal muscle of obese type 2 diabetic patients: a new mechanism of insulin resistance in humans. Diabetologia 2009;52(10):2169-2181.

65. Di Cairano ES, et al. The glial glutamate transporter 1 (GLT1) is expressed by pancreatic beta-cells and prevents glutamate-induced beta-cell death. J Biol Chem. 2011;286(16):14007-14018.

66. Folli F, et al. Altered insulin receptor signalling and $\beta$-cell cycle dynamics in type 2 diabetes mellitus. PLoS One. 2011;6(11):e28050. 